\title{
La razón de la enseñanza. La poesía en los colegios jesuitas del siglo XVIII: pedagogía y bibliotecas (1758-1767)
}

JEAN-Marc BuiguÈs

Université Bordeaux Montaigne

CES.XVIII, núm. 25 (2015), págs. 17-58. 


\section{RESUMEN}

El presente trabajo pretende analizar las Prácticas e industrias para promover las Letras Humana del P. Francisco Javier Idiáquez, una guía para la enseñanza del latín y del griego en los colegios de jesuitas publicada en 1758. El estudio se centrará en determinar qué lugar (horario, niveles, tipo de ejercicios pedagógicos, obras y manuales de poesía) ocupa la poesía en ella a la par que se intentará ver qué evoluciones al respeto ofrecen las Prácticas con la Ratio atque Institutio Studiorum Societatis Iesu de 1598 y el Arte de Nebrija, sobre todo en la versión del P. Juan de la Cerda. Por otra parte, se establecerán las listas de las obras de poesía de los inventarios de las bibliotecas de Colegios de jesuitas de Murcia y Medina del Campo redactados a raíz de la expulsión. El análisis de los libros de poesía se hará en función del origen de los autores (castellanos, catalanes, italianos), de las épocas de redacción y publicación (Antigüedad, Edad media, Renacimiento, etc.) y de los distintos cánones poéticos en debate a mediados del siglo XVIII en España. También se tratará de comparar el corpus de obras aconsejadas por las Prácticas con el abanico de libros de poesía que ofrecían las bibliotecas, de cotejar la teoría y la práctica de la enseñanza de la poesía con las posibles lecturas de poemas que ofrecían las bibliotecas.

Palabras clave

Poesía, enseñanza, jesuitas, Francisco Javier Idiáquez, bibliotecas, siglo XVIII.

RÉSUMÉ

Ce travail se donne pour but d'étudier les Prácticas e industrias para promover las Letras Humanas du P. Francisco Javier Idiáquez, un guide publié en 1758 et destiné à l'enseignement du latin et du grec dans les collèges jésuites. Cette étude se centrera sur deux points: déterminer la place qu'y occupe la poésie (horaires, niveaux, type d'exercices pédagogiques, œuvres et manuels de poésie) et s'efforcer de voir quelles évolutions les Prácticas offrent dans ce domaine par rapport à la Ratio atque Institutio Studiorum Societatis Iesu de 1598 et à l'Arte de Nebrija, surtout par rapport à la version du P. Juan de la Cerda. Par ailleurs, on dressera les listes des œuvres de poésie des inventaires des bibliothèques de collèges de jésuites de Murcie et de Medina del Campo rédigés à la suite de leur expulsion. L'analyse des livres de poésie se fera en fonction de l'origine des auteurs (castillans, catalans, italiens, etc.), des époques de rédaction et de publication (Antiquité, Moyen Âge, Renaissance, etc.) et des différents canons poétiques objets de débats dans les années centrales du XVIIIe siècle en Espagne. Il s'agira également de comparer le corpus d'œuvres conseillées par les Prácticas à l'éventail des livres de poésie qu'offrent les bibliothèques, de confronter la théorie et la pratique de l'enseignement de la poésie aux possibles lectures de poèmes que proposaient les bibliothèques.

MoTS-CLÉ

Poésie, enseignement, jésuites, Francisco Javier Idiáquez, bibliothèques, XVIII siècle.

Recibido: 15 de junio de 2015. Aceptado: 1 de septiembre de 2015. 
Mucho se ha escrito sobre la enseñanza de las letras en los colegios de jesuitas, pero, sin embargo, no abundan los trabajos sobre las posibles inflexiones ocurridas en la segunda mitad del siglo en la Compañía ${ }^{1}$. Este estudio tomará como base principal el proyecto NICANTO ${ }^{2}$. Una de las bases de este proyecto se centra en las bibliotecas institucionales ${ }^{3}$. Se utilizarán los inventarios informatizados de dos bibliotecas de colegios de jesuitas ${ }^{4}$ : el de San Esteban de Murcia y el de Santiago Apóstol el Real de Medina del Campo ${ }^{6}$. La biblioteca de Medina alcanza un total de 1.535 ediciones; la de Murcia, 3.980 ediciones que totalizan 4.673 volúmenes ${ }^{7}$. En el caso del colegio de Medina, los libros de la base NICANTO se corresponden con los que estaban en los aposentos de padres y hermanos, en el refectorio y en dos hospederías, con otros 78 manus-

1 Entre las obras más recientes destacan los trabajos de Javier EsPINo MARTín, Política y gramática en el siglo XVIII: Ilustrados contra jesuitas: Evolución de la enseñanza jesuítica del latín en el siglo XVIII español: la Corona de Castilla, EAE, 2012 y «Enseñanza del latín e historia de las ideas: la revolución de Port Royal y su repercusión en Francia y España durante el siglo XVII», Universidad de Valladolid, Minerva, 23, 2010, págs. 261-284. También Bernabé Bartolomé Martínez, «Educación y humanidades clásicas en el Colegio Imperial de Madrid durante el siglo XVII», Bulletin hispanique, vol. 97, n. ${ }^{\circ} 1$ (1995) (Ejemplar dedicado a: «La Culture des Elites Espagnoles à l'Epoque Moderne»), págs. 109-155

2 NICANTO comenzó en 1993 en la Maison des Pays Ibériques, unidad de investigación sobre el mundo ibérico e ibero-americano de la Universidad Bordeaux Montaigne, proyecto iniciado por tres investigadores: Jean-Pierre Dedieu (Director de investigaciones el CNRS), el añorado profesor François Lopez (Catedrático de la Universidad Bordeaux Montaigne) y un servidor, en aquel momento recién nombrado Profesor Titular en dicha Universidad.

3 Para una visión de conjunto de las bases de NICANTO, véase Jean-Marc Buiguès, «Indexación y códigos en bases de datos bibliográficas», Humanidades Digitales: desafíos, logros y perspectivas de futuro. Janus, Estudios sobre el Siglo de Oro, Anexo 1 (2014), págs. 123-135

4 El punto de partida de esta base fue la lectura de Bernabé Bartolomé Martínez, «Las librerías e imprentas de los jesuitas (1540-1767): una aportación notable a la cultura española», Hispania Sacra, n. ${ }^{\circ} 40$ (1988), págs. 315-388.

5 Esta biblioteca ha sido magníficamente estudiada por María Victoria Játiva MiralLEs, La biblioteca del colegio de San Esteban de Murcia, tesis doctoral, Murcia, 2007, edición consultada en https://digitum. um.es/xmlui/handle/10201/109.

6 Fueron dos las tesinas consagradas a estas bibliotecas y a la informatización de sus librerías entre 1997 y 2000: Gaël Rossillon, La bibliothèque du collège des jésuites de Murcie (1767), Université de Bordeaux III, 1997; Aurore Levadou, La bibliothèque du Collège des Jésuites de Murcie (1767), Université de Bordeaux III, 2000. La elaboración de la base de la biblioteca de Medina no dio lugar a defensa de la tesina.

7 Játiva Miralles, La biblioteca del colegio de San Esteban de Murcia, pág. 265. 
critos que estaban en la «biblioteca común» ${ }^{8}$. Entre los libros que estaban en los aposentos, no es posible distinguir los libros que eran propiedad de los padres y hermanos de los que formaban parte de la biblioteca del colegio, algo que ya señalaron María Victoria Játiva Miralles — «Los libros de las habitaciones de los Padres eran, normalmente, de uso personal relacionados con la materia de la que cada religioso era especialista. No obstante, también poseían libros de la biblioteca común» — y Manuel Peña Díaz — «las larguísimas apropiaciones que, en el tiempo y en el espacio, hacían los miembros de la Compañía debilitaron la función principal de sus bibliotecas» ${ }^{10}$ - Parece incluso que en algunos casos los libros de los aposentos eran del colegio y no de los padres, como revela el análisis del colegio de Bilbao de Bernabé Bartolomé Martínez. De los diecisiete aposentos con libros, tres llevan la mención «vacante» es decir que en el momento del inventario no había padre o hermano pero sí libros que parece ser se vinculaban más a un aposento dado que a un padre en particular ${ }^{11}$. El total de los libros de los aposentos era de 1.668, con una media de 98 libros por celda: los de las tres vacantes sumaban 172 títulos. En Medina, la media era de 51 libros por aposento de padre y de 7 libros para los hermanos.

El cuadro siguiente indica la repartición de los libros del colegio de Medina recogidos en la base NICANTO:

\begin{tabular}{lrr} 
& Títulos & $\%$ \\
\hline Padres & 1.370 & 89,3 \\
Hermanos & 44 & 2,9 \\
Hospederías & 27 & 1,8 \\
Refectorio & 16 & 1,0 \\
Manuscritos que se hallan en la biblioteca común & 78 & 5,1 \\
Total & 1.535 & \\
\hline
\end{tabular}

8 Játiva Miralles aporta datos interesantes sobre los libros que estaban en los aposentos de los padres, La biblioteca del colegio de San Esteban de Murcia, págs. 39, 76 y 171-173.

9 Játiva Miralles, La biblioteca del colegio de San Esteban de Murcia, págs. 39, 76 y 171-173.

10 Manuel Peña DíAz, «La cultura del libro en Andalucía en tiempos de Felipe II», V Reunión Científica Asociación Española de Historia Moderna / coord. por José Luis Pereira Iglesias, José Manuel de Bernardo Ares, Jesús Manuel González Beltrán, vol. 1, 1999 (Felipe II y su tiempo), págs. 529-540. La cita proviene de la pág. 537.

11 Bartolomé Martínez, «Las librerías e imprentas de los jesuitas (1540-1767): una aportación notable a la cultura española», pág. 358. 
En el caso del colegio de Murcia, la biblioteca reunía 4.673 volúmenes, mientras 489 volúmenes estaban en los aposentos de los religiosos, o sea, un $10,4 \%$ del total ${ }^{12}$.

En estos dos inventarios, se han buscado las obras de retórica, de poética ${ }^{13}$ y las ediciones de poesía partiendo del índice de materias establecido por María Victoria Játiva Miralles en su tesis ${ }^{14}$, pero también buscando directamente en la base, sea por nombre de autores (Virgilio, Góngora, etc.), sea por palabras del título («arte/ars», «poética», etc.).

Por otra parte, se ha utilizado el libro del P. Francisco Javier Idiáquez, Prácticas e industrias para promover las Letras Humanas ${ }^{15}$. La obra consta de tres partes: la primera, a modo de guía pedagógica, destinada a facilitar el trabajo en las aulas de la profesores (págs. 11-44); la segunda, que reúne una serie de consejos para fomentar el gusto de la letras entre los alumnos (págs. 45-85); y la tercera, que está basada en una comparación a veces crítica con el «método del Sr. Pluche para aprender las lenguas Latina, y Griega» (págs. 86-141). Idiáquez se refiere a dos obras de Pluche, el tomo 6, «que es el 11 de la traducción del Espectáculo de la Naturaleza en la Carta de un Padre de Familias en orden à la educación de la Juventud» ${ }^{16}$, "La Mecanique [sic] des langues, et l'art de les enseigner» ${ }^{17}$. Para el Espectáculo, Idiáquez indica: «trasladaré algo de ellos de la traducción del P. Terreros» ${ }^{18}$, mientras para la Mécanique será él quien traduzca: «traduciré otros de la Mecánica de las lenguas» ${ }^{19}$. La obra, por tanto, permite a la vez conocer los autores que recomienda Idiáquez y saber cómo se utilizan en las clases.

12 Játiva Miralles, La biblioteca del colegio de San Esteban de Murcia, cuadro pág. 266.

13 Las numerosas ediciones de obras de retórica y de poética presentes en ambas bibliotecas no se analizarán en este trabajo.

14 Játiva Miralles, La biblioteca del colegio de San Esteban de Murcia, págs. 1.529-1.543.

15 P. Francisco Javier Idí́Q̨uez, Prácticas e industrias para promover las Letras Humanas, Villagarcía, Imprenta del Seminario, 1758. La primera edición es de 1753.

16 Idiáquez, Prácticas e industrias para promover las Letras Humanas, pág. 87; las bastardillas son de la edición original. Noël-Antoine Pluche, Spectacle de la nature, ou Entretiens sur les particularités de l'histoire naturelle qui ont paru les plus propres à rendre les jeunes gens curieux et à leur former l'esprit, Paris, Chez la Veuve Estienne, 1732-1742, 9 vols.

17 IdiáQ̨uez, Prácticas e industrias para promover las Letras Humanas, pág. 87; las bastardillas son de la edición original. Noël-Antoine Pluche, La Mécanique des langues et l'art de les enseigner, Paris, Chez la Veuve Estienne, 1735.

18 Esteban Terreros y Pando, Espectáculo de la Naturaleza, o Conversaciones acerca de las particularidades de la Historia Natural. Por el Abad M. Pluche. Traducido al castellano por..., Imprenta de Gabriel Ramírez, Madrid, 1753-55, 16 vols., y Carta de un padre de familias, en orden a la educación de la juventud, de uno y otro sexo. Escrito en idioma francés por el Abad. M. Pluche. Y traducido al español por..., Maestro de Mathemáticas en el Seminario Real de Nobles de la Compañía de Jesús de esta Corte, con algunas notas añadidas al original, Imprenta de Gabriel Ramírez, Madrid, 1754.

19 IDIáquez, Prácticas e industrias para promover las Letras Humanas, pág. 87. 
Para medir la importancia de la obra de Idiáquez es imprescindible recordar que la enseñanza jesuítica era blanco de numerosas críticas fundamentadas en su carácter esclerótico y en el peso que ocupaba la tradición en ella, algo que se oponía al lugar destacado dado al espíritu crítico en la Ilustración. Las Prácticas son la repuesta de los jesuitas españoles, una repuesta inspirada en la obra del P. Jouvancy y cuya meta era renovar la pedagogía en un manual de nuevo corte, en castellano, comentando y precisando cuanto era necesario en el Arte de Nebrija y la Ratio Studiorum.

Un primer eje de trabajo consistirá en delimitar qué lugar (horario, niveles, tipo de ejercicios pedagógicos, obras y manuales de poesía) ocupa la poesía en la enseñanza de los colegios de jesuitas en la década que precede la expulsión de la Compañía, desencadenada por la Pragmática Sanción del 2 de abril de 1767, a la par que se intentará ver qué evoluciones al respecto ofrecen las Prácticas e industrias para promover las Letras Humanas del P. Francisco Javier Idiáquez con la Ratio atque Institutio Studiorum Societatis Iesu de 1598. Por otra parte, se establecerán las listas de las obras de poesía de los inventarios de las bibliotecas de Colegios de jesuitas de Murcia y Medina del Campo redactados a raíz de la expulsión. El análisis de los libros de poesía se hará en función del origen de los autores (castellanos, catalanes, italianos), de las épocas de redacción y publicación (Antigüedad, Edad Media, Renacimiento, etc.) y de los distintos cánones poéticos en debate a mediados del siglo XVIII en España. También se tratará de comparar el corpus de obras aconsejadas por la Ratio Studiorum y las Prácticas e industrias para promover las Letras Humanas con el abanico de libros de poesía que ofrecían las bibliotecas, de cotejar la teoría y la práctica de la enseñanza de la poesía con las posibles lecturas de poemas que ofrecían las bibliotecas.

\section{La poesía integrada a la enseñanza del latín}

La Compañía de Jesús, en los 117 colegios que tenía en España en 1749, consideraba la enseñanza del latín, tanto oral como escrito, como pieza clave del sistema docente iniciado por Ignacio de Loyola e institucionalizado por la Ratio Studiorum. Sin embargo, con el paso de los años, los alumnos españoles del siglo XVIII, y no solo los de los colegios de jesuitas, estudiaban la historia de la poesía tanto latina como castellana, de sus formas, de sus autores a la par que aprendían a versificar y declamar poemas. Dicha enseñanza formaba parte del aprendizaje de la gramática del latín y del castellano, en las partes que correspondían a la retórica, la elocuencia, la prosodia y la propia versificación 
y métrica. Solía empezar después del primer nivel dedicado a las «primeras letras y doctrina cristiana». Los centros de este nivel intermedio que precedían la enseñanza superior, universitaria, etc., eran fundamentalmente las «preceptorías de gramática», los conventos y monasterios de órdenes consagradas a la enseñanza, en particular los colegios de jesuitas, sin olvidar la formación para una pequeña parte de los vástagos de las élites por preceptores privados o incluso por los propios miembros de la familia. Los seminarios, incluyendo los de Nobles creados en el siglo XVIII, los colegios mayores y las universidades formaban el nivel superior en el que algunas facultades dedicaban parte de sus clases a esta formación. Como señala acertadamente Inmaculada Osuna ${ }^{20}$, esta enseñanza de la poesía, tanto como parte de la historia literaria como ejercicio práctico escrito y oral, no tenía en todos los centros ni un idéntico carácter obligatorio, ni una misma finalidad pedagógica o social. Otra faceta de esta actividad centrada en la creación poética era la de los certámenes - a veces de colegiales y estudiantes, a veces de poetas, profesionales y amateurs-, de las tertulias, en particular las literarias, y de las academias, creadas a lo largo del siglo, sin olvidar los exámenes, en muchos casos públicos, en los cuales los alumnos hacían gala de su elocuencia y de su capacidad de crear poemas en ambos idiomas, latín y español. Integrada en la estructura pedagógica o como mero pasatiempo, la poesía era un elemento imprescindible de la cultura de las élites, tanto en la esfera privada (lectura o producción individual) como en la pública (exámenes, certámenes, fiestas, etc.), ora actividad profesional del poeta/autor, ora placeres compartidos en lecturas o recitaciones colectivas, ora extenso impreso o corto pliego suelto.

En la Ratio Studirorum el uso de la poesía se centraba en el primer nivel de estudios, el que abarcaba el mayor número de alumnos, no solo los que deseaban entrar en la Compañía sino también un amplio grupo de vástagos de las élites y grupos intermedios de la sociedad. Este primer ciclo de Estudios Inferiores —la enseñanza jesuítica comprendía tres ciclos, correspondiendo el segundo y tercer ciclo a los Estudios Superiores- «se estructura en cinco años y en ellos se destinan tres cursos a Gramática (elemental, media, superior), uno a Humanidades y uno a Retórica, con las clases distribuidas en dos semestres y los contenidos estrechamente relacionados entre sí» ${ }^{21}$.

El manual central del sistema de enseñanza del latín en los colegios eran las Introductiones Latinae de Nebrija, publicadas en 1481. La obra se volvió

20 Inmaculada Osuna Rodríguez, «Los poetas del Siglo de Oro en textos escolares (siglos XVII-XVIII)», Bulletin hispanique, vol. 109, n. 2 (2007), págs. 615-642.

21 Carmen Labrador Herráiz, «La Ratio Studiorum de 1599. Un sistema educativo singular», Revista de Educación, n. 319 (1999), págs. 117-134. 
obligatoria en todos los centros peninsulares de enseñanza del latín con la promulgación de la Real Cédula de 8 de octubre de 1598. Las críticas por la complejidad del Arte de Nebrija y su difícil uso escolar condujeron a la Real Cédula de Valladolid de 1601, que imponía como manual obligatorio la edición del Arte modificada por el jesuita Juan Luis de la Cerda, padre en el Colegio Imperial de Madrid. Su Aelii Antonii Nebrisensis De Institutione Grammaticae libri quinque, publicado por primera vez en Madrid en 1598, será el texto de referencia de los colegios jesuitas hasta su expulsión en 1767, con numerosas reediciones, siendo las últimas las de 1747 (Herederos de Juan García Infanzón), de 1759 y 1763 (ambas de Joaquín Ibarra), todas madrileñas. Los cambios introducidos por Juan Luis de la Cerda han sido estudiados por María Dolores Martínez Gavilán $^{22}$. La finalidad ${ }^{23}$ de las Prácticas e industrias para promover las Letras Humanas es presentar las «reglas» del Arte de manera distinta, en función de las clases: la organización de la primera parte estaba basada en la estructura pedagógica, como señala el propio Idiáquez en su «Introducción»: «para proceder con más claridad, advierto, que en la lección de memoria, que se señala à cada clase, va repartido el Arte llamado de Nebrija, el cual en realidad viene a ser del P. Juan Luis de la Cerda de nuestra Compañía ${ }^{24}$. En realidad, el proyecto de Idiáquez se inserta en un doble proceso de, por una parte, defensa de la Compañía frente a las críticas, cada vez más fuertes sobre el marcado carácter esclerótico de su enseñanza; y, por otra, de desarrollo de una pedagogía renovada y basada en manuales de nuevo corte.

En los cinco primeros capítulos de las Prácticas se precisan las categorías de alumnos y los ejercicios de las clases de latín y griego. Para cada nivel entre el alumnado (Nivel 1..$^{\circ}$ : Reminimistas; $2 .^{\circ}$ : Minimistas; $3 .^{\circ}$ : Menoristas; $4 .^{\circ}:$ Medianistas; y $5 .^{\circ}:$ Maioristas), la estructura pedagógica es la misma y se divide en tres tipos — «Lección de memoria», «Composición»y «Construcción o versión»- repartidos a lo largo del día. Para evitar la monotonía hay días en que se modifica algo esta estructura. Las obras citadas en estos cinco niveles de estudio empiezan con el nivel inferior de los «Reminimistas». Los tres impresos utilizados en este nivel son: «por la mañana ${ }^{25}$, el primer libro del Arte del P. la

22 María Dolores Martínez Gavilán, «Racionalismo y tradición escolar en el Arte de Nebrija reformado por el P. Juan Luis de la Cerda», Península, Revista de Estudios Ibéricos, n. 4 (2007), págs. 327-346.

23 Análisis parcial en César Chaparro Gómez, «Del De ratione discendi et docendi de Jouvancy a las Prácticas e industrias de Idiáquez: los avatares de la Ratio studiorum jesuita», Cuadernos de Filología Clásica. Estudios Latinos, 34, n. 2 (2014), págs. 315-336.

24 IdiáQuez, Prácticas e industrias para promover las Letras Humanas, pág. 11.

25 Los dos estudios del P. Luis Fernández reunidos en La Casa y el Colegio de Humanidades de Villagarcía de Campos, Bilbao, 1952, ofrecen una buena descripción de la historia del Colegio y de su situación 
Cerda [también por la tarde], llamado de Nebrija» y «algunos renglones de las Epístolas Familiares de Cicerón ${ }^{26} »$, y el «nuevo compendio de modo, o de platiquillas, como regularmente las llaman ${ }^{27}$. Este pequeño manual de 56 páginas enumera en español por clases (primera y segunda clase) las reglas de gramática latina que tienen que memorizar los alumnos, añadiendo al final dos páginas de «Uso de las Calendas, y algunas Cifras Romanas». Los ejercicios además de la lección propiamente dicha versan para la «composición» sobre «nominativos, y verbos» y «algunos días al fin de la composición hágaseles traer trasladados unos cuantos renglones de las reglas de Ortografía, que hai al fin del Arte, para que con el cuidado de trasladar bien, aprendan desde luego a escribir correctamente». Para la «construcción, o versión», «traigan desde el primer día los Reminimistas el Autor, que construien los Menoristas, y aunque todavía no sepan construir, estén atendiendo; pues así se logra el que no metan bulla, el que se hagan à atar la imaginación, el que se acostumbren a leer latín, ù oírle pronunciar, y a que se les imprima la noticia de algunos significados». Inculcar cierta disciplina, espíritu de concentración y cierta familiaridad con el latín a través de un progresivo acercamiento auditivo y basado en la lectura y pronunciación, a la par que alguna que otra memorización, son los elementos que fundamentan esta pedagogía de enseñanza del latín en el primer año.

Los Minimistas (Segundo capítulo) usan en su «Lección de memoria», por la mañana del segundo y tercer libro del Arte de Juan Luis de la Cerda y de las ya citadas Epístolas de Cicerón, memorizando por la tarde el segundo y tercer libro del Arte. Así como también «unos renglones del nuevo compendio de platiquillas». La «Composición» es idéntica a la de los Menoristas «porque aunque al principio no lo harán tan bien, este es mucho menor inconveniente, que el que el Maestro, con tanta pérdida de tiempo, señale composición distinta no solo a Reminimistas, sino también à Minimistas, y Menoristas». Los alumnos tendrán que traducir pequeñas frases del castellano al latín. Parece que la práctica común era que fuesen frases —Idiáquez las llama «romances»— inventa-

en vísperas de la expulsión. El horario era de siete de la mañana a ocho de la tarde, alternando lecciones (en total 3 horas y cuarto) y pasos o estudios (4 horas).

26 Bibliografía importante sobre la recepción de Cicerón en Rosa María Aradra SÁnchez, «Cicerón ilustrado. La recepción de su obra en la retórica española del siglo XVII», Revista de Estudios latinos, n. ${ }^{\circ} 11$ (2011), págs. 185-205.

27 Este manual es el Compendio de los modos de oraciones, que se hallarán en los autores latinos, para facilitar el uso de la traducción, y composición. Pónese al fin un Breve Tratado de las Figuras de Syntasis y Reglas de constituir. Por D. José Félix Cano, Catedrático de Latinidad, y Retorica en la Ciudad de Palencia, Imprenta de Josef de Navas, Burgos (s.a.). Las referencias bibliográficas (BNE, etc.) suelen dar como fecha de impresión 1793, lo que parece imposible dado que Idiáquez señala en su «Introducción» que es la edición de Burgos la que usa: será pues obra recién publicada pero anterior a 1753. 
das por los alumnos. Él quiere que sea el maestro quien las invente. Su crítica es la siguiente: «los romances los ha de dictar el maestro aun à estos principiantes, pues es malísimo el uso de dejar a los Niños, que ellos mismos formen en Castellano las oraciones, que han de traer en latín». Asienta su crítica dando algunos ejemplos de los «romances» inventados por los niños:

[...] y asi vemos à un Niño, que se echa a sí mismo este romance: Los bancos comieron à los bueies: y dice en latin: Subsellia manducaverunt boves. Para una oración de relativo, se echa este otro romance: La Tia Calva, que tiene mal humor, vende las castañas, que vencen a Pedro [...]. Como los pobres Niños solo tienen especies de lo que ven, es à saber, de los bancos, del comer, de los bueies, de la Tía Calva, que es castañera, y de las castañas; no aciertan à echarse à si mismos romances sino de estas, y otras semejantes inanidades ${ }^{28}$.

Al hijo del duque de Granada de Ega, don Francisco Javier de Idiáquez y Aznárez de Garro, le debían de parecer muy rústicos los niños de la campiña de Villagarcía de Campos, aunque sin duda la heterogeneidad real del alumnado fuese muy superior a la que perfilan estos ejemplos cuya función argumentativa y demostrativa es bien patente. El P. Luis Fernández evoca esta heterogeneidad en estos términos: «entre los alumnos anotados aparecen de todas las procedencias de España, predominando, claro está, los de las provincias castellanoleonesas. Provienen de todas las clases sociales y vienen recomendados por personajes de muy diversa alcurnia» ${ }^{29}$. Después de los malos ejemplos, Idiáquez ofrece unos cuantos modelos: "Cuánto más útil es echarles unos romances brevecitos: Julio César escribió comentarios mui latinos; Virgilio, que escribió las glorias de Eneas, compuso un poema, que vence à todas las poesías». Él mismo describe la finalidad docente de tales ejemplos, finalidad que no es meramente gramatical: «después de echados estos romances, en dos palabras esplica el maestro la obra de César, y en otras dos el asunto de la Eneida. Con eso sabe el Niño, que Julio César fue Escritor, qué cosa son comentarios, y que el estilo de César es mui latino, que hubo un Virgilio, un Eneas, una obra llamada Eneida, y que esta obra es el mejor de todos los poemas».

Enseñanza de la historia (César, destrucción de Troya), de los géneros literarios (comentario, poesía épica), y escala de valores («mejor de todos los poemas»), elementos todos que participan de la transmisión de una cultura de la Antigüedad histórica, legendaria y literaria. Concluye con tono algo desprecia-

28 Idí́Quez, Prácticas e industrias para promover las Letras Humanas, pág. 17.

29 Fernández, La Casa y el Colegio de Humanidades de Villagarcía de Campos, pág. 191. 
tivo y humorístico: «que ciertamente son noticias más conducentes, que no las de los bancos comedores de bueies, y de la Tía Calva, de su mal humor, y de las castañas, que vencen à Pedro». La «construcción, o versión» de los Minimistas será la misma que la de los Reminimistas.

Para el tercer nivel, el de los Menoristas, la «lección de memoria» se basará por la mañana en «el libro cuarto de el Arte del Padre la Cerda» y los ya citados «renglones de las Epístolas Familiares de Cicerón», y, por la tarde, además del Arte, el Compendio de Cano. La «composición» es compartida por los tres primeros niveles. La novedad reside para los Menoristas en la «construcción» porque ellos son «los que empiezan a construir, y así primero por la mañana construirán la Epístola de Cicerón, que aprenden de memoria, y se les esplicó, el día antes». Para romper la monotonía de siempre trabajar en las Epistolas, Idiáquez propone «algunos días por la mañana en lugar de Cicerón se les puede hacer construir algunas fabulas, que los alegren, y con la alegría los animen». Si hasta ahora todo lo prescrito no era más que la aplicación de las reglas latinas de Juan de la Cerda, siempre citadas, en este caso Idiáquez va a preferir cambiar la regla: «se construirán en Menores no las fabulas de Esopo traducidas al latín, que se usaban, sino las de Fedro». Justifica este cambio con estas palabras: «aquellas están traducidas por varios Autores, que están mui lejos de ser del siglo de oro». El sencillo hecho de ser traducción y no obra original, la falta de unidad (varios traductores) y el hecho de ser traducciones tardías (no ser del Siglo de Oro) condenan el uso de las Fábulas en latín de Esopo. En cambio las de Fedro, «liberto de Augusto», vienen engalanadas: «son la pureza misma, el candor, y la nata de la latinidad $»^{30}$. Idiáquez tiene una clara periodización de la literatura de la Antigüedad donde afloran las ideas de jerarquía y decadencia, tanto de los autores como del idioma. La edición que recomienda es la suya, «la de Fedro, hecha en Burgos»: seguramente, la de las Fabulas de Phedro, liberto de Augusto en la imprenta de la S. Iglesia siendo su administrador D. Martin de Ojeda y Salazar $(1755)^{31}$. La experiencia de este cambio se expresa a modo de conclusión con: «y lo que no tiene duda es, que la esperiencia enseña, que con Fedro aprobechan mucho los Niños. Niño conozco en estos Estudios de Villagarcía, que en menos de cuatro meses, además de la tarea diaria, ha aprendido de memoria los cinco libros de Fedro». La clase de la tarde será idéntica a la de la Menoristas.

Los Medianistas seguirán con el Arte, el libro quinto, pero con otras obras de Cicerón como «alguna Oración selecta». La clase de la tarde es la que ofrece

$30 \quad$ IdiáQ̨uEz, Prácticas e industrias para promover las Letras Humanas, págs. 18-22.

31 Alberto Gamarra Gonzalo, «Realidad económica y problemática de las imprentas institucionales en el Burgos del Setecientos: los talleres de la Compañía de Jesús y de la Catedral (1745-1766)», Titivillus: Revista internacional sobre libro antiguo, 1 (2015), págs. 405-419. 
más variedad, aunque en parte esté basada en el Arte: «tráigase [...] algunas Elegías de Ovidio de Tristibus, y de Ponto. O alguna égloga, o libro de Virgilio, aunque no las Geórgicas, por ser difíciles para los Medianistas. La regla (de la Cerda) manda que algunos días traigan lección de memoria de algún Poeta». Esta variedad resulta de los nuevos autores (Ovidio y Virgilio) y de los nuevos géneros poéticos (elegía, égloga). Además de explicar y comentar dichos textos, el ejercicio de memorización es importante: de las reglas de la gramática latina, pero también de poesías de la Antigüedad. La traducción de la tarde («Composición») se alarga (hasta «siete renglones») y cobra matices estilísticos con la imitación («se esfuercen [los Medianistas] à imitar el estilo de Cicerón»). La lista de autores cuyo estilo se puede imitar incluye a «Cornelio Nepote, Cesar, Salustio, Livio \&c.», es decir, historiadores romanos. También se inician los Medianistas a la traducción inversa del latín al español, «pues traduciendo el latín à la lengua vulgar, se adelanta mucho en él»; no hacerlo, para Idiáquez, «clarísimo yerro es [...] al no permitir à los Niños traducciones vernáculas de los Autores». El segundo ejercicio de traducción de la mañana es de «Quinto Curcio, que es bellísimo Autor, aunque para los Medianistas, no sería menos oportuno Cornelio Nepote, cuyo librito De Oro tiene un estilo del todo castizo, y cuia historia, ò historias de los Capitanes Generales, por más breves, son más proporcionadas al alcance de los Medianistas, que no la larga historia de Alejandro» ${ }^{32}$. Alude Idiáquez al De Viris Ilustribus, del cual se conservaba la parte consagrada a 24 biografías de generales de diferentes naciones, algunas enemigas de Roma, como Cartago con Aníbal y Amílcar Barca, y sin la menor duda mucho menos extensa que los diez libros de las Historiae Alexandri Magni Macedonis. El estudio de la historia de la Antigüedad tenía como finalidad crear una cultura compartida de las élites, a la par que ofrecerles modelos morales y militares que seguir. Propone Idiáquez que se dedique a la traducción de cada uno un tiempo similar. Por la tarde las construcciones serán de Ovidio, «como se acostumbra, aunque no dañaría el que la segunda fuese algunas veces de algunas églogas, ò algún libro de Virgilio. Las Geórgicas son demasiado difíciles para el común de los Niños, como ya se ha dicho». De nuevo, lo que guía al pedagogo es la adaptación, y buena elección, de obras que correspondan a las capacidades y niveles de los alumnos.

En el nivel superior, el de los Maioristas, se concluirá el estudio del Arte del P. la Cerda con «diez a doce renglones de Cicerón». Los alumnos seguirán ejercitando su memoria con las «selectas de Cicerón; pero mejor sería De Natura Deorum, alguna paradoja, ò alguna Tusculana, ò algún otro libro de Cicerón,

32 IdIÁQ̨uez, Prácticas e industrias para promover las Letras Humanas, págs. 22-26. 
como son De Oratore, De Officiis, y el otro llamado Orato». El diálogo filosófico -De natura deorum, Tusculanae disputationes - y el tratado de ética práctica —De officiis - son dos géneros más que se añaden al de la oratoria. El estudio de Cicerón es la principal base para enseñar la retórica, la filosofía con predominancia del estoicismo - Paradoxa stoicorum - y la estilística. Los Maioristas se dedicarán por la tarde a memorizar ente 8 y 12 versos de Virgilio «y en lo regular de algún libro de la Eneida, del que gustarse al Maestro, escluiendo siempre el libro cuarto, que está prohibido en Nuestros Estudios». La censura literaria y la expurgación eran elementos que permitían a los jesuitas ofrecer una versión moralizada de la Antigüedad. Del mismo modo que Cicerón es el principal autor elegido por Idiáquez para la elocuencia y la oratoria, Virgilio lo es para la poesía: «y que este Poeta [que deben memorizar los alumnos], por lo regular; sea Virgilio, es mucha razón». Sin embargo, también el principio de variedad le permite sugerir: «pero será mui bueno, que algunas veces, ò alguna temporada, en lugar de Virgilio, se les señalen Odas escogidas de Horacio, y especialmente su Arte Poética» ${ }^{33}$. La «composición» sigue basada en las Epístolas de Cicerón, pero también a veces «de propia invención» 0 «dictándoles la sinopsis de alguna de las del mismo Cicerón, que ellos [los alumnos] amplifiquen à su modo». Imitación y creación, pero también prosodia analizando «versos desatados», «haciéndoles señalar sobre cada sílaba la cuantidad correspondiente» ${ }^{34}$. Pormenoriza Idiáquez el método y su progresividad dirigida hacia una mayor autonomía del alumno, que podrá valerse de la biblioteca del colegio:

Un Niño, que sabe, que en cada uno de los renglones están las palabras, de qué ha de constar el verso, se anima à trabar unas con otras las palabras, y al cabo se alegra de ver, que salen sus versos tan corrientes como en el original mismo de Ovidio. [...] Cuando ya los Niños están diestros en trabar así los versos, se les han de dictar sin señalarles la cuantidad. Que esta la busquen ellos mismos en las prosodias ò Diccionarios poéticos ${ }^{35}$.

Idiáquez se vale de un ejemplo basado en dos versos para explicar su pedagogía:

Quid libelli, infelix negotium, mihi vobsicum?

Qui ipse meo ingenio infortunatus perii.

33 IdiáQ̨uez, Prácticas e industrias para promover las Letras Humanas, pág. 27-29.

34 «Cantidad en la prosodia. El tiempo que se tarda en pronunciar una sylaba: como la larga, que gasta dos tiempos, y la breve uno», Diccionario de Autoridades, tomo II (1729).

35 IDIÁQuez, Prácticas e industrias para promover las Letras Humanas, pág. 31. 
En uno, y otro verso hai alguna mudanza de cómo los hizo Ovidio, y es imposible, que el primer verso salga bien con la palabra negotium, como también es imposible, que el segundo salga bien con la palabra infortunatus, y así en este caso se les había de abisar a los Niños, que muden la palabra negotium en el primero, y en el segundo la palabra infortunatus en otras palabras sinónimas; y el que tubiere chiste, ò dicha de que en lugar de la palabra negotium, se le ofrezca la palabra cura, y en lugar de la palabra infortunatus la palabra miser, se llevara la palma, y vendrá à hacer el dístico tan bien hecho como lo hizo Ovidio ${ }^{36}$.

La primera versión de la mañana será de Cicerón: «pueden ser las Oraciones $^{37}$, las Epístolas familiares, las Epístolas à Atico, à Quinto su hermano, De la Senectud, las Paradojas, De los Oficios y otros semejantes de que ya hablé en el $\S$ I. deste capitulo»; la segunda, de «algún Autor histórico, como son César, Salustio, Livio, Curcio, y otros semejantes». En el Parnaso pedagógico de Idiáquez también hay anatemas: "Aquí debo advertir, que de nuestros Estudio se debe desterrar enteramente à Valerio Máximo, por ser Autor de malísimo latín, y tan lejos de pertenecer al siglo de oro que los versados en la lengua latina ponen à Valerio Máximo infra oetatem luteam». Por la tarde la primera traducción será de Ovidio; la segunda, de Virgilio. Este quinto capítulo dedicado a describir las modalidades de la enseñanza del latín se concluye con una valoración muy positiva del Arte Poética de Horacio:

También es razón, que se construia algunos días à Horacio; y lo más útil es su Arte Poética, en la cual marabillosamente se encuentran no solo las reglas de todo género de Poesía, sino también los principios, y abisos mas escogidos para formar, y cultivar el buen gusto en las otras obras de ingenio. Además del Arte Poética de Horacio será conveniente, que se construian algunas odas espurgadas deste escelente Poeta ${ }^{38}$.

El capitulo sexto de la «Parte primera», titulada «Práctica para el uso de buenos libros», empieza con un apartado sobre «algunos libros, que no se han de usar en las Clases». Esta vez el anatema se lanza contra libros religiosos: «no puedo dejar de advertir que no han de construir los Niños ni à San Gerónimo, ni el Concilio de Trento. [...] Las Epístolas de San Gerónimo son un libro mui bueno, y el Concilio de Trento es un libro dignísimo de toda veneración, pero

36 IDIÁQuez, Prácticas e industrias para promover las Letras Humanas, págs. 32-33.

37 «Oración: Razonamiento, locución, arenga, compuesta artificiosamente para persuadir o mover a alguna cosa», Diccionario de Autoridades, tomo V (1737).

38 IDIÁQuez, Prácticas e industrias para promover las Letras Humanas, págs. 33-36. 
cada cosa à su tiempo, y en su lugar» ${ }^{39}$. Lo que denuncia aquí no es el valor intrínseco de estas obras (como para Valerio Máximo), sino el uso muy común de textos previstos para otros fines, en un marco escolar donde su uso es perjudicial. La elección de este tipo de textos — no solo en colegios jesuitas sino también y mucho más en preceptorías de gramática y en conventos- se debía, a veces, a la ausencia de otro soporte educativo (por razones económicas, etc.), pero también muy a menudo a que lo que importaba era, más que el valor didáctico, el contenido ideológico, político, religioso y moral.

El segundo apartado ilustra y defiende la «necesidad de libros de Autores Clásicos». «El Prefecto de los Estudios inferiores es, à quien toca el cuidado de que así Maestros, como Discípulos estén bien surtidos de los libros que comúnmente se usan». Parte de la biblioteca del colegio/seminario tiene que tener no solo los libros de texto que se utilizan en las clases sino bastantes ejemplares para que alumnos y profesores puedan trabajar y estudiar. Sin embargo, parece que la situación de la edición que hoy llamaríamos escolar no permitía conseguirlo: «una esperiencia de muchos años ha hecho conocer, que no se podía lograr el que estubiesen nuestros Estudios surtidos de buenos libros». Jesuita desde 1732, Idiáquez llevaba más de veinticinco años en la Compañía y como Rector sucesivamente de las casas de Burgos y de Villagarcía había vivido directamente esta imposibilidad. La solución que decide poner en marcha es nada menos que la de crear una imprenta en Villagarcía: «para remediar este daño se acaba de tomar la providencia, de que en Villagarcía se ponga imprenta, cuio principal fin es surtir de ediciones de Autores Clásicos, y bien corregidos». Esta política editorial claramente encaminada al abastecimiento de manuales escolares, ya había sido iniciada en la imprenta de Burgos. Al hablar de las «traducciones y notas» (apartado III), indica el Rector que sería provechoso que los alumnos tuviesen las obras y sus traducciones pero que de la sistematización de esta regla resultarían toda una serie de inconvenientes: «1..$^{\circ}$ Que abultarían mucho los libros, que han de llevar a la clase. 2. ${ }^{\circ}$ Que se tardaría mucho en surtirlos de ediciones correctas. 3. ${ }^{\circ}$ Que los libros (y esto es mui digno de consideración) les costarían al doble: y habiendo, como hai, en los Estudios tantos Niños pobres, se les harían más costosos los estudios». Idiáquez toma en cuenta el nivel socio-económico de la mayor parte de los alumnos así como la falta de comodidad si tuviesen que llevar tantos libros, pero también evoca las dificultades de circulación del libro y la falta de ediciones adaptadas a la enseñanza. La solución es la que ya se había iniciado en Burgos: «el remedio está ya en parte tomado, y en parte se continuará en

\footnotetext{
39 IdiáQuez, Prácticas e industrias para promover las Letras Humanas, pág. 37.
} 
tomar. Con la traducción del Fedro, y las Epístolas de Cicerón, que se imprimieron en Burgos, tienen lo bastante para ir rompiendo» ${ }^{40}$. La «traducción de Fedro» es la suya mencionada anteriormente y editada en Burgos en 1755, y las «Epístolas son las Cartas escogidas de M. T. Cicerón, traducidas de latín en castellano, entresacadas de sus Epístolas Familiares, repartidas en varias classes, e ilustradas con algunas notas, para el uso de los principiantes en las Escuelas de Gramática de la Compañía de Jesús, por un Padre de la Misma Compañía» ${ }^{41}$. Idiáquez precisa qué tipo de aparato crítico tendrán las futuras ediciones y cuáles serás sus fines pedagógicos: «ahora se irán haciendo en Villagarcía ediciones con breves sumarios, y breves notas en castellano. Los sumarios fijarán la atención en el asunto, que trata el Autor, y las notas darán luz à los lugares algo obscuros, ò más dignos de observarse, aunque parezcan claros». Están ya sentadas las bases de lo que más tarde, a partir de la segunda mitad del siglo XIX, harán las editoriales especializadas en textos clásicos para los alumnos de los institutos. El programa editorial de Villagarcía prevé, «para probecho de la Juventud», la publicación de ediciones de «Cicerón, de Curcio, de Salustio, de César, de Virgilio, de Ovidio, y de Horacio [...] [y] Cornelio Nepote». Idiáquez justifica la presencia de Fedro (ausente en las primitivas reglas) porque «después que la Compañía formó sus reglas, se aberiguó, que Fedro era el verdadero autor de las Fábulas, que ahora corren con su nombre, y por esta razón se le ha dado entrada en nuestras Clases». Del mismo modo, la elección de Cornelio Nepote se debe a «su estrecha amistad con Cicerón», que «es lo que más debe acreditar su latinidad» así como a su fama: los «tantos elogios [que] se han hecho [de él], y hacen justísimamente» ${ }^{42}$.

Añade el Rector que:

el Horacio se imprimirá con las notas, y paráfrasis en latín, con que le hizo tan apreciable el P. Juvencio. Sería cosa vergonzosa el que los Jóvenes salieran de los Estudios sin haber construido nada de Horacio. Lo más útil es el Arte Poética, en que también se enseña a discurrir, y a hacer crisis ${ }^{43}$ de todo género de obras de ingenio, y por eso lo primero que se imprimirá será el Arte Poética ${ }^{44}$.

40 IdiÁQuez, Prácticas e industrias para promover las Letras Humanas, págs. 40-42.

41 Burgos, Imprenta de la Santa Iglesia por D. Martín de Ojeda y Salazar, 1755, con segunda edición en 1758. El autor podría ser el P. Isidro López.

42 IdiáQuez, Prácticas e industrias para promover las Letras Humanas, págs. 42-43.

43 «Crisis: Juicio que se hace sobre alguna cosa, en fuerza de lo que se ha observado y reconocido acerca de ella», Diccionario de Autoridades, tomo II, 1729.

44 IdiáQuez, Prácticas e industrias para promover las Letras Humanas, págs. 43-44. 
Además de la insistencia sobre la importancia de Horacio y de su Arte Poética, la primera que tendrá que salir de las prensas jesuitas, aclara Idiáquez el papel fundamental del P. Joseph de Jouvancy ${ }^{45}$ en la renovación de la pedagogía y de los manuales de enseñanza del latín y de su literatura en los colegios jesuitas españoles. El Arte, en definitiva, es mucho más que un tratado de poética. Con ella, los alumnos aprenderán a discurrir, es decir, «examinar, pensar y conferir las razones que hai en favor o en contra de alguna cosa, infiriéndolas y sacándolas de sus principios» ${ }^{46} \mathrm{y}$ a «hacer crisis», o sea, elaborar un «juicio que se hace sobre alguna cosa, en fuerza de lo que se ha observado y reconocido acerca de ella» ${ }^{47}$. El Arte se convierte en soporte pedagógico para el análisis basado en la observación, la comparación y el juicio o espíritu crítico que se aplicará en el momento a los textos literarios, pero que servirá luego para cualquier «género de obras de ingenio». Idiáquez ve en ella el instrumento de una formación intelectual que recuerda algunos de los principios de la «Nueva Filosofía», del desarrollo de las ciencias en que los métodos comparatistas y las observaciones son los que permiten la elaboración de la teoría, en que el espíritu crítico es el núcleo alrededor del que todo se organiza.

Por los ejemplares conservados ${ }^{48}$, parece que gran parte del programa editorial fue llevado a cabo en los años siguientes. En 1758, la imprenta villagarciense publicó el Arte Poética de Horacio (De Arte Poetica Liber / cum notis ac perpetua interpretatione P. Josephi Juvencii è Societate Jesu), varias obras de Cicerón (Orationes selectae / argumentis, et notis hispanicis illustratae a P. Josepho Petisco è Societate Iesu; De promptae / notulis hispanicis illustratae ab Josepho Petisco e Societate Iesu y las Elegantes formulae ex omnibus Ciceronis operibus selectae \& ad usum loquendi familiarem accommodatae: pars prima [-quarta]/ Gaspare Sancti... collectore interprete); de Cornelio Nepote (De Vitis Excellentium Imperatorum / breviariis, et Notis Hispanicis illustratus a P. Francisco Xaverio de Idiaquez); de Virgilio (Bucolica / notis hispanicis illustrata a P. Josepho Petisco è Societate Jesu); y de Quinto Curcio (De rebus gestis Alexandri Magni libri VIII / breviariis ac notis hispanicis illustrati... a P. Raymundo Aguirre e Societat. Jesu); además de una Gramática griega / compuesta por el P. Joseph Petisco de la Compañia de Jesus; y ello sin contar varias obras de religión, como

45 Véase el ya citado artículo de César Chaparro Gómez, «Del De ratione discendi et docendi de Jouvancy a las Prácticas e Industrias de Idiáquez: los avatares de la Ratio studiorum jesuita».

46 «Discurrir: Metaphóricamente vale examinar, pensar y conferir las razones que hai en favor o en contra de alguna cosa, infiriéndolas y sacándolas de sus principios», Diccionario de Autoridades, tomo III, 1732 .

47 IdiáQuez, Prácticas e industrias para promover las Letras Humanas, pág. 44.

48 Los resultados provienen de búsquedas en el catálogo de la BNE y el Catálogo Colectivo del Patrimonio Bibliográfico. 
los sermones en latín del jesuita italiano Giulio Cesare Cordara (1704-1785) (L. Sectani Q. Fil., De tota graeculorum hujus aetatis literatura ad gajum salmorium; sermones quator, accessere ad eorum defensionem quintus et sextus) o los de también jesuita Manual Lassala (L. Sectani Q. Fil. De tota graeculorum huius actatis literatura ad gajum salmorium sermones quatuor. Editio septima emendatior $\left.{ }^{49}\right)$; los Abisos del P. Baltasar Álvarez, de la Compañía de Jesús, para juntar virtud con letras; y las Adiciones, y advertencias de N. P. S. Ignacio para hacer bien los egercicios espirituales de Oración....: añádense cuatro meditaciones del mismo Santo Padre... / Por el P. Francisco Xavier de Idiáquez.

Un total de once impresos — doce si añadimos las Prácticas e industrias para promover las Letras Humanas — que patentizan que lo ideado por Idiáquez se había convertido en una de las prioridades de la casa. A modo de comparación, en 1758, Joaquín Ibarra editó unos cuarenta impresos, ipero con un taller que contaba con una decena de prensas!

En 1759, se publicaron obras de Homero (la Batrachomyomachia: Graece \& Latine); de Demóstenes (la Philippica I/ Latinam ex Graeca fecit, \& Analysi Rhetoricá illustravit P. Josephus Juvencius è Societate Jesu); de Virgilio (Aeneis Inotis hispanicis illustrata a P. Josepho Petisco é Societate Jesu in usum scholarum ejusdem Societatis y sus Georgica: notis hispanicis illustrata / a P. Josepho Petisco è Societate Jesu; in usum Scholarum ejusdem Societatis); y de Cicerón (Dialogi de senectute et de amicitia / summariis et notis hispanicis illustrati a P. Josepho Francisco de Isla, è Societate Jesu); así como las Epístolas de San Basilio el Magno (Epistole Tou Meta'loy Basiley Pro's To'n auion Grego'rion tou Theologou / Epistola Magni Basilii ad Sanctum Gregorium theologum: graece \& latine). La calidad tipográfica de estas ediciones se debía a que Idiáquez había conseguido traer de Madrid buenos modelos de tipos de letras griega y latinas, siendo estos más difíciles de conseguir.

Las publicaciones de los años siguientes (1760-1764) mantienen la doble línea editorial de clásicos greco-latinos y de obras religiosas y devocionales. Los clásicos son de Anacreonte (Odae / A. P. Josepho Petisco e Societate Jesu perpetua explicatione illustratae); una serie o colección de cinco volúmenes (Opuscula graeca ad usum Seminarii Villagarsiensis: I. Aesopi Fabulae, II. Anacreontis Odae, III. Epistola M. Basilii, IV. Homeri Batrachomyomachia, V. Demosthenis Philippica); y una obra más de Cicerón (Dialogi de senectute, et amicitia / summariis et notis hispanicis illustrati A. P. Josepho Francisco de Isla è Societate Jesu in usum scholarum eiusdem Societatis). También se publican tres libros más que

49 Las dos ediciones de Lassala y Cordara parecen ser la misma obra. No hemos podido cotejarlas y hemos respetado lo que indican las fichas bibliográficas de las bibliotecas donde se conservan ejemplares. 
completan la edición de los autores clásicos, siendo instrumentos de uso cotidiano que facilitan su estudio y comprensión:

a) Thesaurus hispano-latinus utriusque linguae verbis, et phrasibus abundans / olim a D. Bartholomeo Bravo... inventus; postea a P. Petro de Salas... locupletatus; nunc mendis expurgatus... a P. Valeriano Requejo;

b) De arte rhetorica libri quinque.... / Auctore P. Dominico De Colonia, Societatis Jesu... Accessere in hac novissima editione, Institutiones poeticae / auctore P. Josepho Juvencio ex eadem Societate;

c) Prosodia Villagarsiensis: in duos indices tributa et ex ae, quam Joannes Baptista Ricciolius è Soc. Jesu fusiorem scripsit, excerpta.

El Thesaurus del jesuita Pedro de Salas (1585-1664) es mucho más que un diccionario, incluso especializado en términos poéticos, porque lleva además de los ejemplos sacados de la literatura greco-latina y medieval, una antología de poetas jesuitas:

Esta obra está dividida en tres libros; el primero es un compendio de prosodia latina; el segundo («Epithetorum usum») es un pequeño diccionario poético latino, en el que se ponen por orden alfabético las palabras de uso más frecuente con sus correspondientes epítetos, tomados casi siempre de los autores clásicos; el tercero es un diccionario poético hispano-latino, donde cada palabra castellana va seguida de algunas elegantes «pangendi formulae», tomadas de Horacio, Virgilio, Lucrecio, etc. y de algunos poetas latinos de la cristiandad, como Prudencio, Sedulo, san Jerónimo, etc. Después del vocabulario poético se incluye una antología de poetas jesuitas con el fin de ofrecer ejemplos a los noveles no solo de la poesía clásica pagana sino también de poetas cristianos nacidos en el seno de la propia Congregación. Esta antología de poesía jesuítica comienza con la «España y sus principales ciudades», que pudiera ser del propio P. Salas; le sigue el «Alexias», del P. Francisco Remond, dividido en siete elegías, donde la mujer de san Alejo lamenta la soledad en la que la dejó su marido la misma noche de bodas. A continuación hay una serie de poesías menores: odas, himnos, epigramas, etc., de los padres Bahusio, Caceo, Luis del Cruz, Bercio, Biderman, etc. Del mismo P. Salas es un «Echo in laudem pueri laurea Poëseos donati nomine N. Vera» y un fragmento del canto funerario en alabanza de doña María de Mendoza, fundadora del Colegio de Soria ${ }^{50}$.

50 Jesús Menéndez Peláez, «Teatro jesuítico: La escolástica triunfante y nueva Babilonia del P. Pedro Salas. La tradición del cuento del rey soberbio», Teatro de palabras: revista sobre teatro áureo, 1 (2007), 
Las obras de religión son las siguientes: (i) Doctrinas prácticas, que suele esplicar en sus missiones / el padre Pedro de Calatayud; Practicas espirituales para el uso de los Hermanos Novicios de la Compañía de Jesús, del Noviciado de Villagarcia / por el P. Francisco Xavier de Idiáquez; (ii) Pensamientos christianos para todos los días del mes / compuestos en lengua francesa por el padre Dominico Bohurs [sic] de la Compañía de Jesús; y traducidos en castellano por otro padre de la misma Compañia; (iii) Jardín christiano: compuesto de las flores de varios authores, para la instrucción de la juventud / diole a luz el p. Gabrel [sic] de las Casas; (iv) Catecismo práctico, y... útil para la instrucción y enseñanza... de los fieles y para uso... de los... párrocos y sacerdotes / compuesto por el P. Pedro Calatayud (novena edición); y (v) Modo de oír misa, de confesarse y comulgar con fruto / dispuesto por un Padre de la Compañía de Jesús [s.a.]

Llama la atención la intensidad de la labor editorial de los padres de Villagarcía dado que la mayor parte de las obras no son reediciones — las hay de autores ya difuntos como Baltasar Álvarez (1533-1588), Gaspar Sánchez (15441628), Giovanni Battista Riccioli (1598-1671), Joseph Juvency (1643-1719) y Dominique de Colonia (1660-1741) ${ }^{51}$ — sino ediciones de contemporáneos -Pedro de Calatayud (1689-1773), Giulio Cesare Cordara (1704-1785), Raymundo Aguirre (1720- ?), Manuel Lassala (1738-1806): todos jesuitas, franceses, italianos y españoles-. Controlar las ediciones de estos autores, imprimirlas y asegurar su venta y difusión ya es una tarea impresionante, pero todavía más lo es la de los tres jesuitas de Villagarcía, que llevaron a cabo las nuevas ediciones ideadas por Idiáquez con su nuevo aparato crítico. El P. Isla se responsabilizó de dos ediciones, las Geórgicas de Virgilio y el diálogo De senectute, et amicitia de Cicerón; poco, comparado con la labor de Idiáquez y de Petisco, pero hay que tener en cuenta que ya cumplía 55 años, que tenía problemas de salud y que estaba redactando la Historia del famoso predicador fray Gerundio de Campazas, alias Zotes, cuya primera parte fue publicada en 1758. Idiáquez es el responsable editorial de tres obras — pero asumía el cargo de Rector del Colegio/Seminario-, dos de religión (Adiciones, y advertencias de N. P. S. Ignacio para hacer bien los egercicios espirituales de Oración y Doctrinas prácticas, que suele esplicar en sus missiones el padre Pedro de Calatayud) y el De Vitis Excellentium Imperatorum de Cornelio Nepote, obra tan querida por él que la llamaba «librito de oro» y consideraba que su estilo era «del todo castizo». Sin

págs. 123-154; cita en págs. 124-125. En línea en http://www.uqtr.ca/teatro/teapal/TeaPalNum01Rep/Menendez.pdf.

51 Interesante es el estudio de Ricardo MARtínez ORTEGA sobre la difusión de la Retórica de Colonia: «La influencia de la «Retórica» de Domingo de Colonia en la Dispositio del ms. 83-3-25 de la Universidad de La Laguna», Cuadernos de Filología Clásica. Estudios latinos, n. 16 (1999), págs. 413-422. 
embargo, el más prolífico es José Petisco, con seis ediciones: el Arte Poética de Horacio, las Bucólicas y la Eneida de Virgilio, las Odas de Anacreonte, las Oraciones selectas de Cicerón y una Gramática griega.

\section{El Parnaso didáctico de poetas griegos}

El tercer apartado del segundo capítulo de la tercera parte que examina las obras de Pluche, intitulado «De la lengua griega», trata de los «Libros, y egercicios para la lengua griega». No se analizarán por ahora las estrategias pedagógicas sino únicamente los libros que Idiáquez recomienda. Distingue dos niveles de estudio del griego, el de los «principiantes» y el de «los más adelantados». Los del primer nivel son «los Libros Griegos à propósito para los Niños, son los que señala la regla de la Compañía Reg. 9. Prof. Hum. Estos son además del Catecismo Griego para los principiantes, las Fábulas de Esopo, y la Tabla de Cebetes». La lista de los libros para los alumnos más adelantados es mucho más extensa:

Para los más adelantados, entre los Oradores Isócrates, Demóstenes, Platón, S. Gregorio Nacianceno, S. Basilio, S. Chrisostomo, Sinesio. Entre los Poetas Homero, Hesíodo, Píndaro, Focílides, Teógnides, y las Poesías de S. Gregorio Nacianceno, y de Sinefio. Entre los Historiadores Tucídides, Xenofonte, y Plutarco [...] Y por tanto serán mui útiles los Diálogos de los muertos de Luciano, el Manual de Epicteto. Las Odas espurgadas de Anacreonte, algún Idilio escogido de Teócrito, algunas Tragedias de Sófocles y Eurípides, algunos Epigramas y Elegías de Calímaco, Heródoto, Dionisio Halicarnaseo, Polibio, y Herodiano ${ }^{52}$.

La nómina de poetas abarca un amplio marco cronológico desde los más antiguos, griegos o alejandrinos - Homero, Anacreonte, Calímaco, Píndaro, Focílides el Milesio, Teócrito, Teognis de Mégara y Hesíodo-, hasta los bizantinos o romanos — Gregorio Nacianceno y Sinesio—. Idiáquez no indica de manera sistemática cuáles son las obras de cada poeta, salvo cuando especifica los géneros: fábulas (Esopo), odas (Anacreonte), elegías (Calímaco) y epigramas. Quizás los epigramas sean los de la Antología Palatina, editada por primera en vez 1491 por Máximo Planudes y que recoge mayormente epigramas de poetas griegos. También se puede entender el texto de Idiáquez, «algunos Epigramas, y Elegías de Calímaco», como las elegías y las epigramas de Calímaco. Sin

\footnotetext{
52 IdiáQuez, Prácticas e industrias para promover las Letras Humanas, pág. 137.
} 
embargo la pedagogía preconizada por el Rector impone que se reduzca cuanto más esta nómina a dos escritores de cada género, dos oradores, dos historiadores y dos poetas:

Esto no es decir, que se haia de usar de todos estos Autores, ni de muchos dellos, sino de uno, ò dos Oradores, de uno, ò dos Poetas, y de uno, ò dos Historiadores. Quien quisiere saber el aprecio, que se merece cada uno destos Autores, lea al P. Joseph Juvencio en su Iibrito de oro intitulado': Christianis literarum Magistris de ratione discendi, \& docendi. I. part. cap. I. art. I. § 2. y cap. 2. art. $3^{53}$.

Como ya se ha analizado anteriormente, se ve claramente la influencia en Idiáquez del P. Joseph de Jouvancy quien servirá de filtro en la elaboración de este Parnaso didáctico de la literatura griega destinada a los alumnos.

El cuadro siguiente sintetiza la información sobre las poesías en latín y en griego que propone lo que, bajo varias modalidades, estudiaban colegiales y seminaristas, distinguiendo la información que proviene de la descripción de las clases por niveles (Minimistas, Menoristas, etc.), de la que recoge las ediciones hechas en Villagarcía y las obras recomendadas para el estudio del griego.

\begin{tabular}{|c|c|}
\hline Nivel de enseñanza & Obras para las clases \\
\hline Minimistas & Ejercicio de traducción que permite presentar la Eneida \\
\hline Menoristas & Eneida de Virgilio / Fábulas de Fedro \\
\hline Medianistas & Elegías de Ovidio / Bucólicas de VirgiLio \\
\hline Maioristas & Eneida de Virgilio / Arte poética de Horacio \\
\hline \multicolumn{2}{|r|}{ Ediciones de la imprenta de Villagarcía } \\
\hline \multicolumn{2}{|r|}{ Horacio, Arte Poética } \\
\hline \multicolumn{2}{|r|}{ VIRGILIO, Bucólicas } \\
\hline \multicolumn{2}{|r|}{ Homero, Batrachomyomachia } \\
\hline \multicolumn{2}{|r|}{ Virgilio, Eneida } \\
\hline \multicolumn{2}{|r|}{ Anacreonte, Odas } \\
\hline \multicolumn{2}{|r|}{ Esopo, Fábulas } \\
\hline & Pedro de Salas, Thesaurus \\
\hline
\end{tabular}

53 IdiáQ̨uez, Prácticas e industrias para promover las Letras Humanas, pág. 138. 
Obras de «poesía» recomendadas para el estudio del griego

$\begin{array}{cc}\text { Homero } & \text { Focílidies el Milesio } \\ \text { Esopo, Fábulas } & \text { Teognis de Mégara } \\ \text { Anacreonte } & \text { Hesíodo } \\ \text { Calímaco } & \text { Gregorio Nacianceno } \\ \text { Píndaro } & \text { Sinesio }\end{array}$

\section{Libros de poesía en dos librerías de colegios de jesuitas}

Sin embargo, la información que proporcionan los inventarios de las bibliotecas de colegios de jesuitas a raíz de su expulsión en 1767 permite completar este primer panorama. Los dos colegios de Murcia y de Medina del Campo ${ }^{54}$ informatizados en NICANTO ofrecen una pequeña muestra de la riqueza de aquellos fondos, que desafortunadamente los límites impuestos a este trabajo no darán lugar a profundizar. No obstante, las listas dadas a continuación demuestran que los libros de poesía que poseían los jesuitas permitían tanto a los padres como a los colegiales y/o seminaristas no sólo tener a mano amplias series de poesías grecolatinas sino también de poetas «modernos»y «contemporáneos» ${ }^{55}$. El cuadro siguiente presenta el balance general de la investigación en los inventarios.

$\begin{array}{lcc} & \text { Poetas «modernos» } & \text { Poetas grecolatinos } \\ \text { Medina del Campo } & 11 & 22 \\ \text { Murcia } & 48 & 12\end{array}$

La comparación de las dos bibliotecas pone de realce grandes diferencias en los libros que se ofrecían a los lectores —docentes o alumnos—: en la de Medina del Campo solo la tercera parte son de autores «modernos», cuando en la de Murcia los «modernos» alcanzan el $80 \%$.

Son varios los impresos de poesía grecolatina presentes en las bibliotecas que vienen a completar las listas de los libros preconizados por Idiáquez. En

54 Al retomar la indexación que se había hecho en los años 1997-2000 de la biblioteca de Medina aparecieron fichas todavía sin hacer, lo que significa que el corpus estudiado es incompleto. Una lectura provisional de estas fichas ha permitido encontrar obras de Francisco Ruiz de León y antologías poéticas que no se han podido incluir en este trabajo.

55 Utilizamos aquí la palabra «modernos» con el sentido de autores posteriores a la Antigüedad y anteriores al siglo XVIII, y «contemporáneos» como nacidos después de 1680. 
algunos casos se trata de autores recomendados por el Rector, pero en ediciones distintas o en obras no mencionadas (Homero, Virgilio, etc.); en otros casos, se trata de autores que habían quedado fuera de su panteón didáctico: Ovidio, Juvenal, Lucano, Marcial, Sidonio Apolinar y Minitius Fundanus. Del mismo modo, ensanchan este panorama dos antologías de la librería del Colegio de Murcia - Carmina quinque hetruscorum poetarum nunc primum in lucem edit (Florencia, Junta, 1568) y Carmina nouem illustríum feminarum Sapphus, Myttidis, Prazillae, Erinnae, Corinnae, Nossidis, Myrus, Telesillae, Anytae. Et lyricorum Alomanis, Ibyci, Stesichori, Anacreontis Alcaei, Simonidis, Bacchylidis. Elegiae Tyrtaei, \& Mimnermi. Bucólica Bionis \& Moschi / Latino versu a Laurentio Gambara expressa; Cleanthis, Moschionis, aliorumque fragmenta nunc primum edita; Ex bibliotheca Fuluii Ursini Romani (Amberes, Cristóbal Plantino, 1568)—, y una del colegio de Medina de Ottavio Fioravanti Mirandula - Illustrium poetarum flores, per Octavianum Mirandulam collecti, \& in locos communes digesti-. Cabe también subrayar la gran difusión de las ediciones salidas de las prensas de Villagarcía, más importante en el Colegio de Medina (7 ediciones), sin duda por su proximidad geográfica, que en el de Murcia (2 ediciones).

La poesía en «romanze» ofrecía también un amplio abanico que arrancaba con poetas de finales de la Edad Media (Ausiàs March) y concluía con poetas contemporáneos (Gerardo Lobo, Joaquín Navarro, etc.). Medina poseía ocho impresos y un manuscrito de poesía; Murcia, veintidós, pero la biblioteca murciana era dos veces más grande que la de Medina.

Aunque el concepto de «nacionalidad» no tenga el mismo significado que hoy día, sobre todo cuando la obra se edita en latín, hay representados poetas franceses, flamencos, alemanes (como moradores del espacio del Santo Imperio Romano Germánico), italianos, portugueses y españoles. El cuadro siguiente ofrece una visión de conjunto de las nacionalidades:

\begin{tabular}{lrr}
\hline «Nacionalidad» & Número & $\%$ \\
\hline portugués & 2 & 3,7 \\
alemán & 2 & 3,7 \\
flamenco & 2 & 3,7 \\
francés & 7 & 13,0 \\
italiano & 13 & 24,1 \\
español & 28 & 51,9 \\
Total & 54 & \\
\hline
\end{tabular}


Los poetas portugueses constituyen el grupo menos representado (menos de 5\%) con Camões y Adame de Montemayor. Los del norte —Flandes: Torentius, Wallius y el Santo Imperio: Pontanus, Balde - también representan menos del $5 \%$. Un segundo grupo ya más nutrido lo componen los franceses (13\%) con Dorat, Caussin, Hoschius, La Fontaine, Nomessy y Le Jay, seguidos por los italianos (21\%) con Alciato, Corradi, Florengi, Alamanni. El grupo mayoritario lo componen los españoles, que representan la mitad del total. La quinta parte de los autores son jesuitas. Muchos de los impresos son de poesía sacra, pero también profana, incluso a veces hay ediciones de ambas poesías de un mismo autor. En cuanto a las épocas, a grandes rasgos, los poetas se reparten del modo siguiente:

\begin{tabular}{|lrr}
\hline \multicolumn{1}{|c}{ Época } & Número & \multicolumn{1}{c}{$\%$} \\
\hline XIV & 1 & 1,9 \\
XV & 2 & 3,8 \\
XV-XVI & 1 & 1,9 \\
XVI & 17 & 32,1 \\
XVI-XVII & 5 & 9,4 \\
XVII & 16 & 30,2 \\
XVII-XVII & 3 & 5,7 \\
XVIII & 9 & 17,0 \\
Total & 54 & \\
\hline
\end{tabular}

La época dominante es el siglo XVII, con la mitad del total; pero, sin embargo, los poetas contemporáneos, los del siglo XVIII, alcanzan un no desdeñable $20 \%$, indicio que los jesuitas se mantenían, en parte por lo menos, al tanto de las novedades. En cuanto al XVI, alcanza un 27\%, siendo el siglo XV el menos representado, solo con las poesías de Ausiàs March y de Francesco Patrizi (un $7 \%$ ). Otro aspecto importante es la progresiva españolización: para los siglos XIV y XV, hay cinco poetas italianos y un flamenco, y solo un español. La situación cambia en el siglo XVII, donde solo hay un flamenco, un alemán, un italiano y cuatro franceses cuando los españoles ya son nueve, más de la mitad. En el siglo XVIII, solo uno de los seis poetas no es español. Otros enfoques que serían posibles - la censura jesuita de los poetas, los géneros poéticos, las fechas y lugares de edición, etc.— de momento no los estudiaremos. 


\section{Conclusión}

El Parnaso poético-didáctico grecolatino que elabora Idiáquez refleja el último intento —antes de la salida forzosa de 1767- de los jesuitas españoles por renovar la enseñanza de las humanidades e intentar silenciar las cada vez más numerosos y fuertes voces que se elevaban en contra del estancamiento y la «barroquización» de su sistema educativo. El papel de Idiáquez y del grupo de excelsos jesuitas que le rodeaba en Villagarcía de Campo fue fundamental, asumiendo el liderazgo del proceso renovador que abarcaba no sólo una reforma parcial de las prácticas pedagógicas establecidas por las reglas adaptándolas a lo que eran realmente sus alumnos, pensando en sus dificultades, en los obstáculos que provenían de su estirpe social o de sus escasos recursos económicos, sino también cambiando algunos de los autores que tradicionalmente conformaban el corpus pedagógico de la Compañía y, sobre todo, poniendo en marcha una exigente y novedosa política editorial de manuales que con mucha probabilidad tenían, $m u$ tatis mutandis, como modelo la prestigiosa colección francesa ad usum Delphini compuesta por sesenta y cuatro volúmenes publicados entre 1670 y 1698.

Por lo tanto no se pueden reducir las lecturas de los alumnos - y todavía menos las de los padres jesuitas - a este tan bien definido y restringido Parnaso villagarciense. Los inventarios de las librerías de los jesuitas constituyen una innegable fuente para ampliar este panorama. Esbozan unas posibles lecturas que abarcan la cultura grecolatina pero también las creaciones en lenguas vernáculas de los siglos XV, XVI, XVII y XVIII. Evidentemente faltan muchos autores, y a veces de «primera fila», en este Parnaso bibliotecario doblemente ampliado, en el tiempo y por los idiomas que lo componen. Tampoco tenemos que confundir nuestros Parnasos fundamentalmente elaborados por críticos y especialistas del tema desde el siglo XIX con los de épocas anteriores.

Dos bibliotecas jesuitas del centenar que existían en 1767 igualmente son una bien limitada muestra. Sin duda que el estudio de otras bibliotecas - algunas ya analizadas pero que no hemos podido incluir en este trabajo como la de Granada, etc.- permitiría elaborar un panorama más completo. Otro eje necesario, pero que sólo un equipo de especialistas podría llevar a cabo, sería el elaborar un diccionario de las citas y referencias a poetas y poemas en las publicaciones de los jesuitas del siglo XVIII. Por fin, no se pueden descontextualizar las poesías y los poetas que estudiaban los alumnos y los jesuitas de las retóricas ${ }^{56}$, orato-

56 Sin ser exhaustivos, las bibliotecas poseían las retóricas de Colonia (17 ejemplares de la edición de Villagarcía en el colegio de Medina), de Soarius, del Brocense, de Suárez etc., las oratorias de Bartholomeus Bravus, etc., las poéticas de Gaspar Díaz, de Rengifo, etc. 
rias y artes poéticas que eran como los miembros de una misma familia y como tales necesitarían otro estudio específico. Como tampoco se pueden descartar las lecturas, tanto de alumnos como de los padres, de libros de otras bibliotecas o prestados por amigos y relaciones.

Como ya se ha señalado, los padres además de acceder a los libros de la biblioteca de su colegio también tenían en sus celdas pequeñas bibliotecas privadas. Entre los libros que estaban en los aposentos de los padres del colegio de Murcia, sólo se mencionan estas obras de poesía: las obras de Góngora ${ }^{57}$, los sonetos y canciones en italiano de Sannazaro, los epigramas latinos de Prudencio y varias obras de Virgilio (Eneida y Bucólicas). Sin determinar si eran propiedad de los padres o préstamo de la biblioteca, lo cierto es que estas obras estaban en un espacio de lectura privada. Si la presencia de obras de Virgilio se explica por ser obras que servían en la enseñanza, las de Góngora, Sannazaro y Prudencio podrían reflejar lecturas y gustos más personales. En el colegio de Medina, los libros se reparten entre seis aposentos de hermanos y veintisiete de padres. Ninguno de los hermanos tiene libros de poesía en su habitación; veintidós padres reúnen unas 67 ediciones de libros. Ocho de cada diez padres poseen libros de poesía; pero, sin embargo, como refleja el cuadro siguiente, tres grupos distintos se definen:

\begin{tabular}{|cc|}
\hline N.o de títulos & N.o de aposentos \\
\hline 1 & 10 \\
2 & 5 \\
4 & 2 \\
5 & 1 \\
6 & 2 \\
20 & 1 \\
\hline
\end{tabular}

El primer grupo lo componen los que poseen entre uno y dos libros: es el caso de quince padres, para los cuales la poesía no representa mucho. El se-

57 Todas las obras de don Luis de Gongora: en varios poemas / recogidas por don Gonzalo de Hozes y Cordoua, Madrid, Imprenta Real: a costa de la Hermandad de los Mercaderes de libros de Madrid, 1654. 
gundo lo conforman los cinco padres que poseen entre 4 y 6 libros $^{58}$. El caso del padre «Juan Mattheo Carrera» con veinte obras constituye un caso excepcional. Sin embargo, resulta difícil sacar conclusiones en la medida en que tanto las posibles funciones docentes como los gustos personales podrían explicar esta presencia de libros de poesía en los aposentos.

Otra pregunta difícil de contestar es la de la difusión y aceptación de la obra de Idiáquez. Los únicos datos encontrados son los siguientes. La obra no figura en la biblioteca del colegio de Murcia, sí en el de Medina, donde está en el aposento del «P. Juan Mattheo Carrera». También se menciona en el inventario de 1767 del Colegio de Salamanca. En este inventario, se indican los libros que estaban en las celdas de algunos padres. En realidad, en este caso no se trata de su biblioteca privada, sino más bien de los libros que se vendían en la portería de su colegio ${ }^{59}$. El inventario del Colegio de Salamanca de 1767 menciona los libros que estaban en la celda del P. Rada. Entre las 46 obras, que sumaban un total de 6.223 ejemplares que almacenaba en su celda el P. Rada, figuran 18 ejemplares de las Prácticas e industrias para promover las Letras Humanas, por un valor de 18 reales $^{60}$. Si la presencia de los 18 ejemplares atestigua su difusión, sin embargo dista mucho de los miles de novenas o de libros del P. Calatayud que el colegio vendía. A pesar de todo, la fuerte centralización del poder jesuítico y la tendencia a la homogeneización que durante dos siglos caracterizó la pedagogía de los padres permite suponer que las Practicas tuvieron amplia difusión cuando no certera aplicación.

Una evaluación del número potencial de los alumnos susceptibles de haber recibido una enseñanza de la poesía según las normas de Idiáquez entre 1759 y 1766 arroja unos 30.000 discípulos ${ }^{61}$. Aunque suponiendo que no todos recibieron semejante enseñanza, la cifra es importante. Entre ellos, cuando ya adultos, no todos fueron lectores de poesía y aún menos fueron poetas, pero, sin embargo, la pasión por la poesía en particular y por las humanidades en general que se mantendrá hasta finales del siglo y de la cual dan una idea los numerosos debates, las tertulias y academias, y las publicaciones tanto en libros como en

\footnotetext{
58 Son los padres «Francisco Xavier Calbo», «Pedro Garcia», «Fernando Chico», «Juan Sandoval»y «Juan Antonio Ximenez».

59 Publicamos un estudio de los libros de las celdas de los padres que vendía el Colegio de Salamanca: Jean-Marc Buıguès, «Las lecturas más comunes de los españoles en el siglo XvIII», Bulletin Hispanique, vol. 100, n. $^{\circ} 2$ (1998), págs. 515-530.

60 Buiguès, «Las lecturas más comunes de los españoles en el siglo XVIII», pág. 529.

61 El modo de cálculo de esta evaluación es el siguiente: 146 colegios de jesuitas con una media de 50 colegiales totalizan 7.500 alumnos. Los alumnos que estudiaban poesía eran los de tercer y cuarto año. Entre 1759 y 1766 son cuatro cohortes (La de 1759 termina su quinto año en 1763, la del 60 en el 64, la del 61 en el 65 y la del 62 en el 66). Las cuatro cohortes totalizan 30.000 alumnos.
} 
la prensa, esta pasión, decíamos, compartida por las élites tradicionales y los nuevos lectores de los grupos intermedios de las ciudades ${ }^{62}$, se debió, en parte por lo menos, a la renovada labor educativa de los jesuitas.

\section{Documentos anexos}

I. Libros de Poesía del COLegio de Murcia ${ }^{63}$

\section{A. Poetas «modernos»}

«Montemayor (Fran[cis]co), Vida en verso de S[an] Pedro / Apostol, 4. ${ }^{\circ}$, Madrid, $1598 »$.

Adame De Montemayor, Francisco (hac.1538-1559), Nacimiento, vida, y muerte del Apostol S. Pedro, Príncipe de la Yglesia / por el Licenciado Francisco Adame de Montemayor, clérigo. En Toledo: por Pedro Rodríguez, 1598, 4. .

«Alciatí (Andree), Emblemae, 8. ${ }^{\circ}$, Matriti, 1735; Parisiis, 1589».

Alciati, Andrea (1492-1550), Omnia Andreae Alciati V.C. emblemata cum commentariis... / per Claud. Minoem, Parisiis: apud Franciscum Guessier, $1589,8 .^{\circ}$.

«Alamani (Luis), Poesías varías, 8. ${ }^{\circ}$, Venecia, 1542 (En / italiano)».

Alamanni, Luígí (1495-1556), Opere toscane / di Luigi Alamanni, Venetiis: apud haeredes Lucae Antonii luntae, 1542, 8..

«Baldi (Jacobi) Sfocietatis] J[esu], Opera Poética íl2. ${ }^{\circ}$ Coloniae/1660, tom[o]s, ls. et $4 \mathrm{~s}$ ».

Balde, Jacob, (S.I.) (1604-1668), Poemata [t. I-IV], Coloniae Vbiorum: apud loannem Busaeum, 1660, 12. .

«Borja (Fran[cis]co), Obras poéticas, 4. ${ }^{\circ}$, Madrid, 1648».

62 Sobre los progresos de la alfabetización en el siglo XVIII véanse los estudios de Jacques SouBEYRouX «Niveles de alfabetización en la España del siglo XVIII. Primeros resultados de una encuesta en curso». Revista de historia moderna, (1985), págs. 159-172 y de Antonio VIÑAO, «Alfabetización e ilustración, diez años después (de las evidencias directas a las indirectas)», Bulletin Hispanique, vol. 100, n. ${ }^{\circ} 2$ (1998), págs. 255-269.

63 Por orden alfabético de autores. El primer texto de cada dupla corresponde a la entrada original del inventario; el segundo, a la identificación que hemos realizado de cada edición en concreto. 
BorJa, Francisco de (1582-1658), Las obras en verso de Don Franco de Borja Príncipe de Esquilache, Madrid, Diego Díaz de la Carrera, 1648, 4. .

«Brabo (Nicolás), Poesías varias, $4 .^{\circ}$, Salamanca, 1604».

Bravo, Nicolás (O. Cist.) (1587-1648), Benedictina / de F. Nicolás Brauo, monge cisterciense; en que trata la milagrosa vida del glorioso S. Benito; con vna breue recapitulación de las religiones que le reconocen por Padre, assí monásticas como militares, Salamanca, Imprenta de Artus Tabemiel, $1604,4 .^{\circ}$.

«Camoes (Luis), Lusiadas, $4 .^{\circ}$ (Sin principio, ni fin)».

Camóes, Luis de (ca. 1524-1580), Os Lusiadas / de Luis de Camoes, Impressos em Lisboa, em casa de Antonio Gosaluez, 1572, 4.‥

«Castelvi (Joacfiin), Poema eroico, 4. ${ }^{\circ}$, Valencia, 1745».

Castelvi y La Figuera, Joaquín (siglo XVIII), Mercurio sacro y poético en el qual se contienen algunas noticias tocantes a los progresos que cursa las Escuelas del Seminario de Nobles de San Ignacio y Certamen literario de el año escolar 1745 / su autor Don Joachin Castelvi y la Figuera. En Valencia: en la oficina de Joseph Estevan Dolz, [1746], 4. .

«Cerda (Ludovici) S[ocietatis] J[esu], Comentaria in Virgilio, f., 2 tom[o]s, Lugduni, 1617».

CerdA, Juan Luis de la (S.l.) (1560-1643), P. Virgilii Maronis posteriores sex libri Aeneidos: argumentis explicationibus notis ilustrati / auctore Ioanne Ludovico de la Cerda. Societatis lesu, Lugduni: sumptibus Horatii Cardón, 1617, Fol.

«Cevae (Thomae) S[ocietatis] J[esu], Poema latini, 8. ${ }^{\circ}$, Venetiis, 1732».

Ceva, Tomás (S. I.) (1648-1737), Jesús puer: poema / Thomae Cevae e Societate Jesu, Venetiis: ex typographia Gasparis Girardi, 1732, 8. .

«Valdés (Pedro), Poesías varías, a S[an] Luís Gonzaga, 4.․, Córdoba, 1728».

Clemente Valdés, Pedro (siglo XVIII), Amphitheatro sagrado desde cuyas tres órdenes de asientos se pueden ver los espectáculos celebres y magníficos que ofreció el Máximo Colegio Cordobés de la Compañía de Jesús para aplaudir en su canonización a S. Luis Gonzaga y S. Estanislao Kostka / Pedro Clemente Valdes, Impresso en Córdoba: en casa de Juan Ortega y León mercader de libros: por Acisclo Cortes, 1728, 4.․ 
«Corradi (Sebastiani), In Virgilio Eneidas, 8. ${ }^{\circ}$, Fio / rentiae, 1572».

Corradi, Sebastiano (1510-1556), Sebastiani Coradi comentarius in quo P. Virgilii Maronis liber primus Aeneidos explicatur, Florentiae: excudebat Laurentius Torrentinus, 1572, 8. ${ }^{\circ}$.

«Corte, Real (Gerónimo), Poesías varias, 8. ${ }^{\circ}$, Alcalá, 1597».

Corte Real, Jerónimo (1533-1588), La verdadera historia, y admirable succeso del segundo cerco de Diu, estando don Iuan Mazcarenhas por Capitán, y Gouernador de la fortaleza / compuesto por Gerónimo Corte real; traducido en lengua castellana, por Fray Pedro de Padilla carmelita. Impresso en Alcalá de Henares: en casa de Iuan Gradan, 1597, 8. .

«Dávila (Juan), Pasión del hombre Dios en decimas /castellanas, f., Barcelona, $1661 »$.

DÁvILA, Juan (S.I., siglo XVII), Passión del Hombre-Dios: referida y ponderada en decimas españolas / por el maestro Iuan Dáuila. En León de Francia: a costa de Horacio Boissat y Gorge Remeus, Claudio Bourgeat y Miguel Lietard, mercaderes de libros, 1661, Fol.

«Aurati (Joannis), Epigramata, 8. ${ }^{\circ}$, Parisiis, 1585».

Dorat, Jean (1508-1588), Ioannis Aurati lemouicis poetae et interpretis regij Poématia. Lutetiae Parisior: apud Gulielmum Linocerium in monte Diui Hilarij, ad insigne vasis aurei, 1586, 8. .

«Ercilla (Alonso), Cantos de la Aurocana, 4. ${ }^{\circ}$ (Sin / principio, ni fin)».

Ercilla y ZúñIGa, Alonso de (1533-1594), Primera y segunda parte de La Araucana de don Alonso de Ercilla y Quñiga. En Madrid: en casa de Pierres Cosin, 1578, 4. ${ }^{\circ}$; Tercera parte de la Araucana. Madrid: En casa de Pedro Madrigal, $1589,4 .^{\circ}$.

«Poesías varías, $4 .^{\circ}, 1662 »$.

Fernandez De Rozas, Gabriel (siglo XVII), Noche de invierno. Conversacion sin naypes en varias poesias castellanas divididas en dos partes, La priemra, de assuptos graves, y sacros. La segunda, de assumptos de burlas, Madrid, por Francisco Nieto, 1662.

«Cocai (Merlíni), Macaronicorum, 12. ${ }^{\circ}$, Venetiis, 1563».

Folengo, Teófilo (O. S. B) (1493-1544), Opus Merlíni Cocaii poetae mantuani macaronicorum, totum in pristina[m] formam per me Magistrum Acquarium 
Lodolam optime redactum. Venetiis: apud Beuilacquam, 1564 (apud Nicolaum Beuilaquam), 12. .

«Gómez (Albari), Musa Paulina, 8. ${ }^{\circ}, 1519 »$.

Gómez De Ciudad Real, Álvaro, Musa Paulina Aluari Gómez. Compluti: in aedibus Michaelis de Eguia, 1529, 8.․

«Góngora (Luis), Obras poéticas, 4. ${ }^{\circ}$, Madrid, 1654».

Góngora y Argote, Luis de (1561-1627), Todas las obras de don Luis de Gongora: en varios poemas / recogidas por don Gonzalo de Hozes y Cordoua. En Madrid: en la Imprenta Real: a costa de la Hermandad de los Mercaderes de libros de Madrid, 1654.

«Guarino (Bautista), Tragedia del Pastor Fido, 4. ${ }^{\circ}$, Venecia, 1602 (En italiano)». GuarinI, Giovanni Battista (1538-1612), II pastor Fido, tragicommedia pastorale: Ora in questa XX. impressione di curióse, \& dotte annotationi arricchito, \& di bellissime figure in rame ornato. Con un compendio di poesia tratto da i dúo Verati / con la giunta d'altre cose notabili per opera del medesimo S. Cavaliere. Venetia appresso G. B. Ciotti, 1602, 4. .

«López de Zárate (Fran[cis]co), Obras poéticas, $4^{\circ}$, Alcalá, 1651».

López De Zarate, Francisco (1580-1658), Obras varias de Francisco López de Zarate. En Alcalá: por Maria Fernandez: a costa de Tomas Alfay mercader de libros, 1651, $4 .^{\circ}$.

«Lobo (Eugenio), Obras poéticas, $4 .^{\circ}$, Pamplona, 1754».

Lово, Eugenio Gerardo (1679-1750), Obras poéticas / de Don Eugenio Gerardo Lobo. Dedicadas en esta segunda ediccion [sic] al mismo autor / y añadidas de una tercera parte y corregidas y emmendadas. En Pamplona: por Joseph Ézquerro, 1724, $4 .^{\circ}$.

«Marsch (Ausias), Obras Poéticas, 8. ${ }^{\circ}$, Valladolid, 1555».

March, Ausias (1397-1459), Las obras del poeta mosen Ausias March: corregidas de los errores que tenían. Sale con ellas el vocabulario de los vocablos en ellas contenidos [compuesto por Juan de Resa]. Impresso en Valladolid: en casa de Sebastiá Martínez, 1555, 8. .

«Mata (Gabriel), Poesías varias, 4. ${ }^{\circ}, 2$ tom[o]s, Logroño, 1569».

Mata, Gabriel de, Segundo uolumen del Cauallero Asisio de F. Gabriel de Mata 
en las gloriosas vidas de cinco famosos sanctos de su orden, S. Clara, S. Antonio de Padua, S. Buenauentura, S. Luys Obispo de Tholosa, y San Bernardino. Impresso en Logroño: por Mathias Mares, 1589, 4.․

«Speliensis (Fran[cis]ci), Poemae variae, 8. $^{\circ}$, Florentiae, 1571».

Mauri, Francesco (O. F. M.), Francisci Mauri. Francisciados libri XIII. Florentiae: apud Carolum Pectinarium, 1571, 8. ${ }^{\circ}$.

«Minturni (Antonius), De ofitiis ecclesiae, 8. ${ }^{\circ}$, Venetiis, 1564».

Minturno, Antonio Sebastiano (1500-1574), Antonii Sebastiani Minturni epigrammata et elegiae. Venetiis: apud Io. Andream Valuassorem, 1564, 8. .

«Sebastíani (Antonius), Poemata varia, 8. ${ }^{\circ}$, Venetiis, 1564».

Minturno, Antonio Sebastiano (1500-1574), Antonii Sebastiani Minturni, Poemata, ad Consaluum Pyretium, summi consilij apud catholicum regem virum primarium. Venetiis: apud Io. Andream Valuassorem, 1564 (Venetiis: apud Io. Andream Valuassorem, 1564).

«Navarro (Joachin), Poesías varías, $4 .^{\circ}$. Madrid, 1762».

NaVARro, Joaquín (S.l.) (1705-1780), La hermosura sin lunar, qual es la del alma y cuerpo de Maria Santísima significada en su uida: escrita en estancias de canción real y según la reueló la Señora a su sierua la M. Maria de Jesús de Agreda / su autor el P. doctor Joachin Nauarro de la Compañía de Jesús. Madrid por Joachin Ibarra, 1762, 4. .

«Nomesei (Nicolai), Parnasus poeticus, $12 .^{\circ}$ [Lugdufni], 1616».

Nomesseius, Nicolaus [NOMESSY, Nicolas de], Pamassus poeticus biceps / collectus primum, ac non segniter labore [et] studio Nicolai Nomessei; hunc excepit generalis orbis descriptio, Graecorúmque motum nativa enarratio. Lugduni: Sumptibus Petri Rigaud, 1625, 12. .

«Orozco y Covarrubias (Juan), Emblemas morales, 4. ${ }^{\circ}$, Zaragoza, 1604».

Orozco Y Covarrubias, Juan de (1540-1608), Emblemas morales de don Iuán de Horozco y Couarruuias. En Qaragoca: por Alonso Rodríguez: a costa de Iuán de Bonilla, 1604, 4.․

«Patricio (Fran[cis]co), Tratado de la poesía, $4 .^{\circ}$, Ferrara, 1586 (En italiano)». Patrizi, Francesco, Obispo de Gaeta (1413-1494), Della poética di Francesco Patrici la deca istoriale. In Ferrara: per Vittorio Baldini, 1586.4.‥ 
«Petreio (Joannis), Epigrama latinae, 8. ${ }^{\circ}$, Toleti, 1552».

Perez. Juan (1512-1545), Ioannis Petreii toletani Oratoria eloquentis. necno \& poetae ingeniosis. libri quattuor in laudem diuae Mariae Magdalenae; vna cum alijs eiusdem opusculis in fine adiectis. Toleti: apud fratres Ferrarienses, $1552,8 .^{\circ}$.

«Maripetro (Geronimo), El Petrarca espiritual, 8. ${ }^{\circ}$ (En italiano)».

Petrarca, Francesco (1304-1374), II Petrarca spirituale (Sonetti et Canzoni di F. Petrarcha divenuto thedogo et spirituale per studio di fratre Hieronymo Maripetro). Al fin: Venetia: s.n. (1545), 8.

«Petrarca con exposición de Alejandro Villutello , 4. ${ }^{\circ}$, Venetiis, 1544».

Petrarca, Francesco (1304-1374), Il Petrarcha con l'espositione dAlessandro Vellutello / di novo ristampato con le figure a $i$ Triomphi et con piu cose vtili in varii luoghi aggiunte. In Venetia: appresso Gabriel Gioli di Ferrarii, 1544 (1543), 4. .

«Polo (Jacinto), Poesías varías, 4. ${ }^{\circ}$, Madrid, 1715»

Polo De Medina, Salvador Jacinto (1603-1676), Obras en prossa, y verso, de Salvador Jacinto Polo de Medina / recogidas por u aficionado suyo. En Madrid: en la imprenta de Angel Pasqual: a costa de Pedro del Castillo, 1715, 4. ${ }^{\circ}$

«Pontani (Jacobi) S[ocietatis] J[esu], Floridorium, 8. Ingolstadi, 1602» Pontanus, Jacobus (S.l.) (1542-1626), Jacobi Pontani de Societate lesu Floridorum libri octo : Accessit item hymnorum liber singularis in ordines caelestium. Ingolstadii: Ex Typographia Adami Sartorii, 1602, 8. ${ }^{\circ}$

«Quebedo (Fran[cis]co), Parnaso español, 4. ${ }^{\circ}$, Madrid, 1668».

Quevedo, Francisco de (1580-1645), El parnaso español y musas castellanas / de don Francisco de Quevedo Villegas. Corregidas i enmendadas de nueuo en esta impression / por el doctor Amuso Cultifragio. (En Madrid: por Melchor Sánchez: a costa de Mateo de la Bastida, 1668, 4.․

«Rueda (Antonio), Justa poética en aplausos / de S[an] Luis Gonzaga, y Estanislao Koosca, 4. ${ }^{\circ}$, Murcia, 1727».

Justa poética: celebrada en el Colegio de la Compañía de Jesús, de Murcia, el dia 17 de noviembre de 1727 en culto de S. Luis Gonzaga y de S. Estanislao de Kostka / por Don Antonio de Rueda Marin, secretario. En Murcia: por Jayme Mesnier, en la calle de la Platería, [s.a.], 4. ${ }^{\circ}$. 
«Leon (Fran[cis]co), Obras poéticas, 4. ${ }^{\circ}$, Madrid, 1755».

Ruiz De León, Francisco (1683-1765), Hernandia, Triumphos de la fe y gloria de las armas españolas: poema heroyco, conquista de México proezas de Hernán Cortes y grandezas del Nuevo Mundo / lo cantaba Francisco Ruiz de León. En Madrid: en la imprenta de la viuda de Manuel Fernandez y del Supremo Consejo de la Inquisición, 1755, 4. ${ }^{\circ}$.

«Sanazaro, Sonetos y canciones, 8. ${ }^{\circ}$, 1534 (S.L.), (En italiano)».

Sannazaro, Jacopo (1455-1530), A. Synceri Sannazarij opuscula elegantissima ac legetibus utilissima Quibus additi sunt libri dúo de gestis Apostoloru, neutra in parte inferiores, Aratoris presbyteri. Compluti: In Aedibus Michaelis de Eguia, 1534, 8. ${ }^{\circ}$ [Es muy probable que se trate en realidad de la edición de Roma de 1530].

«Stroce (Thomas) S[ocietatis] J[esu], Poemata varia, Neapoli, 1689, 8. ${ }^{\circ}$. Strozzi, Tomás (1631-¿?) (S.I.), P. Thomae Strozae Neapolitani e Soc. Jesu Poemata Varia. Neapoli: Ex nova Officina Dom. ant. Panino \& Michaelis Aloysii Mutii, 1689, 8. .

«Taso (Torquato), Gerusalem conquistada, 4. ${ }^{\circ}$, Genova, 1590 (En italiano)». TAsso, Torquato (1544-1595), Della Gierusalemme liberata di Torquato Tasso / annotationi de Scipio Gentili], In Genova: appresso Girolamo Bartoli, 1590, $4^{\circ}$.

«Taso (Torquato), Obras poéticas [i.e. 12..$^{\circ}$, 4 tom[os], Roma, 1651 (En italiano) [edición sin identificar $]^{64}{ }^{\star}$.

«Torrenti (Levini), Poema sacra, 8. ${ }^{\circ}$, Antuer / piae, 1594 (Apolillado)».

Torrentius, Laevinus (1525-1595), Laeuini Tonrentii. Poemata sacra. Antuerpiae: ex Officina Plantiniana apud viduam \& loannem Moretum, 1594, 8. .

«Torres (Diego), Poesías varias, 4. ${ }^{\circ}$, Salamanca, 1738».

Torres Villarroel, Diego de (1693-1770), Juguetes de Thalia, entretenimientos de el Numen. Varias poesias que escribió D. Diego de Torres Villarroel, Salamanca, por Antonio Villarroel, 1738, 4. ${ }^{\circ}$.

64 Se menciona una edición cuya fecha no corresponde: TAsso, Torquato (1544-1595), II Goffredo, ouero Gierusalemme liberata, poema heroico del sig. Torquato Tasso. Con l'allegoria vniuersale dell'istesso. et con gli argomenti del sig. Horatio Ariosti. Aggiuntoui cinque canti del sig. Camillo Camilla. In Roma: per Franc. Caualli: ad istanza di Flaminio Mattei, 1639, 12. . 
«Tarsis (Juan), Obras poéticas, 4. ${ }^{\circ}$, Madrid, 1643».

Villamediana, Juan de Tarsis, Conde de (1580-1622), Obras de don Iuán de Tarsis conde de Villamediana, y Correo Mayor de Su Magestad / Recogidas por Dionisio Hipólito de los Valles. En Madrid: por Diego Diaz de la Carrera: a costa de Diego Martínez Hartacho, 1643, 4. ${ }^{\circ}$.

«Bietma (Guillen), Obras de Horacio con decía / ración castellana, f., Granada, 1599».

Villen De Biedma, Juan [HORACio FlaCo, Quinto], Q. Horacio Flacco poeta lyrico latino: sus obras con la declaración magistral en lengua castellana / por el doctor Villen de Biedma. En Granada: por Sebastian de Mena: a costa de Iuán Diez mercader de libros, 1599, Fol.

\section{B. Poetas grecolatinos ${ }^{65}$}

«Carmina illustríum terminarum, 8. ${ }^{\circ}$, Antuerpiae, 1568. G. L».

Carmina nouem illustríum feminarum Sapphus, Myttidis, Prazillae, Erinnae, Corinnae, Nossidis, Myrus, Telesillae, Anytae. Et lyric,orum Alomanis, Ibyci, Stesichori, Anacreontis Alcaei, Simonidis, Bacchylidis. Elegiae Tyrtaei, \& Mimnermi. Bucólica Bionis \& Moschi / Latino versu a Laurentio Gambara expressa; Cleanthis, Moschionis, aliorumque fragmenta nunc primum edita; Ex bibliotheca Fuluii Ursini Romani. Antuerpiae: ex officina Christophori Plantini, 1568, 8. .

«Carmina quinque etruscorum poetarum, 8. ${ }^{\circ}$, 1562, Florentiae».

CARMINA quinque hetruscorum poetarum. Florentiae: Apud Iuntas, 1562, 8. .

HoMero

«Homerii, Opera, f., 1541 (s. l.)».

«Cum Joannis Spondani, f., 2 tom[o]s, Basileae, 1583. G.L. (Apolillado)».

Homeri quae extant Omnia, llias, Odyssea, Batrachomyomachia, Hymni, Poematia aliquot / cum Latina versione. Perpetuis in lliada simul et Odysseam Io. Spondani commentariis. Pindari quin etiam Thebani Epitome Iliados \& Daretis Phrygii de bello Troiano libri, a Com. Nepote eleganter latino versicarmine. Basileae: Eusebii Episcopii opera ac impensa, 1583.

65 Se incluyen los autores latinos cristianos. Como se puede ver, no todas las referencias han sido identificadas todavía. 
«Cum Joannis Spondani, 8. ${ }^{\circ}$ Luduni, 1541».

Prudencio Aurelio Clemente (348 d. C.-c. 410)

«Prudente (Aureli), Epigramma latini, 12. ${ }^{\circ}$, Parísiis, 1662».

Sidonio Apolinario (430-480)

«Apolinaris Sidonii, Poema adgue Epistolae, F. voir Sidoine Apollinaire».

Virgilio Maron, Publio

Virgilii (Maronis) Eneidas, 8. ${ }^{\circ}$, Venetiis, 1543.

«P. Virgilii Maronis Opera / nunc recens accuratissime castigata cum XI acerrimi iudicii virorum commentariis Servii \& Donati ex antiquii exemplaribus ad suam integritatem pristinum [at]q[ue] candore restitutis; addita familiari interpretatio[n]e Ascensii cum annotationibus Christophori Landini, Augustini Dathi \& Philippi Beroaldi; quibus accedunt castigationes varietates que Virgilianae lectionis per loannem Pierium; Omnibus exactiori cura quám unquam alias excusis restitutis locis suis graecis ómnibus dictionibus], Venetiis: apud Iuntas, 1543, fol.».

«Eclogas cum Joannis Vivis, f., Venetiis, 1602».

P. Virgilii Maronis. Universum poema / cum absoluta Seruii Honorati Mauri \& Badij Ascensij interpretatione. Venetiis [s.n.], 1602, fol.

«Virgilii Fastorum et Eneidas, 8. ${ }^{\circ}, 2$ tom[os], Villagarsiae, 1660».

P. Virgilii Maronis Geórgica / notis hispanicis illustrata a P. Josepho Petisco é Societate Jesu. Villagarsiae: typis Seminarii, 1760, 8. .

«Ursini (Fulvi) Virgilius colatione scríptoru $[m]$ / grecarum, 8. ${ }^{\circ}$, Antuerpiae, 1568».

Virgilius collatione scriptorum graecomm illustratus opera et industria Fulvii Ursini. Antuerpiae: Ex officina Christophori Plantini, 1568 (Al fin: 1567), 8. .

«Virgilii cum Maurí Severí, f., Parísiis, 1600 (Descuadernado, y falto de ojas)». Pub. Virgilii Maronis Bucolicomm, eclogae X; Georgicomm, libri VI; Aeneidos, libri XII / et in ea, Mauri Servii Honorati grammatici commentarii ex Bibliotheca Petri Danielis. Accessit Fabii Planciadis Fulgentii liber de continentia virgiliana. Item lunii Philargyrii commentariolus in Bucólica et Geórgica Virgilii. Parisiis: apud Sebastianum Nivellium, 1600, Fol. 


\section{Libros de poesía del colegio de Medina del Campo ${ }^{66}$}

\section{A. Poetas modernos}

«Poetara flores [sin principio]».

«Mirandula, Ottavio Fioravanti, Illustrium poetarum flores per Octavianum Mirandulam collecti et in locos communes digesti [hubo 12 ediciones entre 1538 y 1616]».

«Anónimo, Versos varios («Manuscritos que se hallaron en la biblioteca común $\left.{ }^{67} »\right)$.

«Causino (Nicolas) (1583-1651), Symbolos traduzido del latin y aumentado con varias observaciones por don Francisco de la Torre y Sevil, Madrid, 1677».

«Fontaine (Mons de la), Fables choisies mises en vers, Amsterdam, 1693».

Fables Choisies Mises En Vers. Amsterdam, Daniel De La Feuille, 1693-1694, 5 partes en un volumen, $12 .^{\circ}$.

«Guarini (Baptista), Il pastor fido, Paris, 1678».

«Hoschius (Sidronius), (1596-1653), Poemata, Lugduni, 1688».

«Lejai (Gabriel Franciscus), Biblioteca retori precepta complectens ad poeticam facultate, Venetiis, $1741 »$.

«Polo (Jacinto), Govierno moral, Varcelona, 1678».

«Quebedo (Francisco), Sus obras, Madrid, 1664».

«Revoles (Pedro Lucas), Berde ramo en aplauso de san Pedro regalado compuesto en berso».

Verde ramo del sacro laurel de Apolo en aplauso de los sagrados cultos y prophanos festejos, con que la ciudad de Valladolid, solemnizó la canonización y exaltacion a las sagradas aras de San Pedro Regalado fundador de la obser-

${ }^{66}$ La identificación de las ediciones está en proceso y por ello no se indica sistemáticamente como en el caso anterior.

67 Son 58 los manuscritos conservados en la denominada «biblioteca común». 
vancia Regular de San Francisco, en España, desde el dia veinte del mes de Junio, hasta el día seis de Julio del año de mil setecientos y quarenta y siete.

«Salas (Petrus), Thesaurus poetara, Vallisoleti, 1631».

Salas, Pedro de (1585-1664) (S.I), Thesaurus Poetarum Continens Syllabarum quantitatem omnium et totam versificando rationem. Epitheta Illustrium Poetarum phrases. In gratiam ivventutis Poëtices studiosae defossus, Vallisoleti, Hieronymum Morillo, 1631, 8. ${ }^{\circ}$

«Walius (Jacobus), Poematta tomus primus et secundus, Parisiis, 1723».

B. Poetas grecolatinos

AnACReonte

«Pettisco (Josephus), Ode Anacreontis, Villagarsia, 1761».

Esopo

«Nabarrete, Notas a las favulas de Isopo, Villagarcia, 1761».

«ssopi, Favule, Villagarsia, $1761 »$.

FEDRO

«Augusto (Fedro Libertto), Fabulas en romanze, Burgos, 1755».

«Favulas de Fedrocii expositionibus, Burgos, 1745».

Fundanus, Minitius

«Fundanus (M.), Phrases poetice, Musiponti, 1606».

HoMero

«Omeri, Battrachomiomachia, Villagarsia, 1759».

«Omerus, Sus Iliadas».

Horacio

«Flacus (L. Horatius), Carmina expurgatta, et acuratis notis illustrata a Patre Josepho Jubencio, Venetiis, 1755».

JUVENAL

«Iubenalis (Junius), Sattire, Londini, 1612».

«Iuvenalis (Junius), Satyre, Lugduni, 1549». 
LUCANO

«Lucanus (Marcus), Pharsalia, Parisiis, 1512».

MARCIAL

«Martialis (Valerius), Epigrammata, Lugduni, 1612».

«Martialis (Valerius), Epigrammata, Venetiis, 1501».

OvIDIO

«Naso (Ovidius), Ejus opera, Vallisoleti».

«Obidio (P. Nason), Commentado por Don Ignacio Suarez de Figueroa, Madrid, $1733 »$.

«Obidius (Publius Naso), Metamorphosios Lugduni, 1566».

VIRGILIO

«Maro (Virgilius), Ejus opera, Venetiis, 1542».

«Virgillus (P. Maro), Ejus opera cu commentariis Carolirueus duo tomi identici, Venetiis, 1713».

«Virgillus (P. Maro), Ejus opera cu notis, Amstelodami, 1677».

«Virgillus (P. Maro), Ejus opera cum notis Anttonii de Lloya sine principio».

«Pettisco (Josephus), Bucolica Virgilii illustratta, Villagarsia, 1758».

III. Cuadro de los poetas «modernos y contemporáneos» del Colegio de Murcia

\begin{tabular}{|c|c|c|c|}
\hline Colegio & Poeta & Siglo & «Nacionalidad» \\
\hline Murcia & Petrarca, Francesco (1304-1374) & XIV & italiano \\
\hline Murcia & MARCH, Ausiàs (1397-1459) & $\mathrm{XV}$ & español \\
\hline Murcia & Patrizi, Francesco, Obispo de Gaeta (1413-1494 & $\mathrm{XV}$ & italiano \\
\hline Murcia & SANNAZARO, Jacopo (1455-1530) & $\mathrm{XV}-\mathrm{XVI}$ & italiano \\
\hline Murcia & Gómez De Ciudad Real, Alvaro & XVI & español \\
\hline Murcia & MAтA, Gabriel de fr. & $\mathrm{XVI}$ & español \\
\hline Murcia & Villen De Biedma, Juan & $\mathrm{XVI}$ & español \\
\hline Murcia & CoRTE-REaL, Jerónimo (1533-1588) & XVI & español \\
\hline Murcia & Torrentius, Laevinus (1525-1595) & XVI & flamenco \\
\hline Murcia & DORAT, Jean (1508-1588) & XVI & francés \\
\hline
\end{tabular}




\begin{tabular}{|c|c|c|c|}
\hline Colegio & Poeta & Siglo & «Nacionalidad» \\
\hline Murcia & Alciato, Andrea (1492-1550 & $\mathrm{XVI}$ & italiano \\
\hline Murcia & Corradi, Sebastiano (¿?-1556) & $\mathrm{XVI}$ & italiano \\
\hline Murcia & Folengo, Teófilo (O.S.B) (1493-1544) & $\mathrm{XVI}$ & italiano \\
\hline Murcia & Alamanni, Luígí (1495-1556) & $\mathrm{XVI}$ & italiano \\
\hline Murcia & Minturno, Antonio Sebastiano (1500-1574) & XVI & italiano \\
\hline Medina & GuARINI, Baptista (1538-1612) & $\mathrm{XVI}$ & italiano \\
\hline Murcia & Camoes, Luis (1525-1580) & $\mathrm{XVI}$ & portugués \\
\hline Murcia & Adame De Montemayor, Francisco & XVI & portugués \\
\hline Murcia & PÉREz, Juan (1512-1545) & XVI & español \\
\hline Murcia & MAURI, Francesco & $\mathrm{XVI}$ & italiano \\
\hline Murcia & TAsso, Torquato (1544-1595) & $\mathrm{XVI}$ & italiano \\
\hline Murcia & Pontanus, Jacobus (S.l.) (1542-1626) & XVI-XVII & alemán \\
\hline Murcia & ERCILLA, Alonso de (1533-1594) & XVI-XVII & español \\
\hline Murcia & Horozco Y Covarrubias, Juan de (1540-1608) & XVI-XVII & español \\
\hline Murcia & CERDA, Juan Luis de la (1558-1643) (S.I.) & XVI-XVII & español \\
\hline Murcia & GóngORA Y ARGOTE, Luis de (1561-1627) & XVI-XVII & español \\
\hline Murcia & BALDE, Jacob (1604-1668) (S.I.) & XVII & alemán \\
\hline Murcia & Villamediana, Juan de Tarsis, Conde de (1580-1622) & XVII & español \\
\hline Medina & Quevedo, Francisco de (1580-1645) & XVII & español \\
\hline Medina & Polo De Medina, Salvador Jacinto (1603-1676) & XVII & español \\
\hline Murcia & Lopez De ZÁrate, Francisco (1580-1658) & XVII & español \\
\hline Murcia & Quevedo, Francisco de (1580-1645) & XVII & español \\
\hline Murcia & BoRJA, Francisco de (1582-1658) & XVII & español \\
\hline Murcia & Bravo, Nicolás Fr. (1594-1648) & XVII & español \\
\hline Murcia & Polo De Medina, Salvador Jacinto (1603-1676) & XVII & español \\
\hline Murcia & DÁvILA, Juan (S.I.) (siglo XVII) & XVII & español \\
\hline Medina & W ALIUS, Jacobus (1599-1690) & XVII & flamenco \\
\hline
\end{tabular}




\begin{tabular}{|c|c|c|c|}
\hline Colegio & Poeta & Siglo & «Nacionalidad» \\
\hline Medina & Caussin, Nicolas (1583-1651) & XVII & francés \\
\hline Medina & Hoschius, Sidronius (1596-1653) & XVII & francés \\
\hline Medina & La Fontaine, Jean de (1621-1695) & XVII & francés \\
\hline Murcia & Nomessy, Nicolás de (siglo XVII) & XVII & francés \\
\hline Murcia & STRozZi, Tomás (1631-¿̨ ?) (S.I.) & XVII & italiano \\
\hline Medina & LE JAY, Gabriel-François (1657-1734) (S.I.) & XVII-XVIII & francés \\
\hline Murcia & CEva, Tommaso (1648-1737) (S.I.) & XVII-XVIII & italiano \\
\hline Murcia & Castelvi Y La Figuera, Joaquín ( siglo XVIII ) & XVIII & español \\
\hline Medina & RevolÉs, Pedro Lucas ( siglo XVIII ) & XVIII & español \\
\hline Murcia & Lово, Eugenio Gerardo (1679-1750) & XVIII & español \\
\hline Murcia & Ruiz De León, Francisco (1683-¿1765?, ¿1783?) & XVIII & español \\
\hline Murcia & NAVARRo, Joaquín (S.l.) (1705-1780) & XVIII & español \\
\hline Murcia & Cleemente ValdÉs, Pedro (siglo XVIII ) & XVIII & español \\
\hline Murcia & FERnÁndez De Rozas, Gabriel (siglo XVII) & XVIII & español \\
\hline Murcia & RuEDA, Antonio & XVIII & español \\
\hline Murcia & Torres Villarroel, Diego de (1693-1770) & XVIII & español \\
\hline
\end{tabular}

